\title{
A Comparison of Zirconia and Titanium Abutments for Microleakage
}

\author{
A Thesis \\ Presented in the partial fulfillment of the Requirement for \\ The degree Master of Science \\ In the graduate School of the Ohio State University
}

BY

Mohamed Abdelhamed, BDS

Graduate Program in Dentistry

The Ohio State University

2010

Committee

Dr. Binnaz Leblebicioglu (Advisor)

Dr. Julie Holloway

Dr. Edwin McGlumphy 


\section{Copyright by}

\section{Mohamed Abdelhamed}

2010 


\begin{abstract}
Background: The existence of a microgap in two-piece implant system has been well documented in the literature. This microgap is in microns size and several in-vitro studies tested the microleakage through the microgap and its effect on hard and soft tissues. It was proven that this gap acts as a reservoir for bacteria which induced peri-implant tissue inflammatory reactions. Microleakage through the interface differ between implant bodyabutment connections systems and study methodology. There is an increased demand for all ceramic crowns and zirconia abutments in the anterior sextant due to esthetic reasons. To our knowledge there is not enough information regarding leakage around zirconia abutments. Thus it was the purpose of the study to compare titanium abutments and zirconia abutments for microleakage under two different torque values.

Materials and Methods: Thirty two dental implants, sixteen titanium abutments and sixteen zirconia abutments were used in this study. Four study groups: [Group A (titanium abutment torqued at $25 \mathrm{Ncm}$ ), Group B (titanium abutment torqued at $15 \mathrm{Ncm}$ ), Group C (zirconia abutment torqued at 25Ncm) and Group D (zirconia abutment torqued at $15 \mathrm{Ncm})]$ were included. Micro-CT technology was chosen to scan the assemblies for the detection of a microgap. Microleakage from the implant chamber to the external milieu was evaluated using LAL test while microleakage from the external milieu to the implant chamber was evaluated using toluidine blue dye and colorimeter to detect color change.
\end{abstract}


Statistical Analysis: Data was analyzed using Two-way Analysis of Variance (ANOVA) with Benferroni post test. The level of statistical significance was set at alpha=0.05.

Results: Micro-CT images could not detect microgap at a resolution of 9.7 micron. LAL test showed that there is a time dependent increase in microleakage independent from abutment time or closing torque and a statistically significant difference was detected within zirconia abutment with closing torque value of $15 \mathrm{Ncm}(\mathrm{P}<0.05)$. The toluidine blue test showed that there is no statistically significant time effect on microleakage independent from abutment type/torque value although leakage increased in general with time. Repeated torque/anti-torque does not have a statistically significant effect on microleakage although more leakage was noted with titanium abutment torqued/antitorqued several times. Also there was no statistical significant difference in microleakage through the screw access hole in the four different groups.

Conclusion: With in the limit of this in-vitro study, it can be concluded that there is no statistically significant difference in bidirectional microleakage between titanium and zirconia abutments at different closing torque values in non-loading condition. However there is a significant increase in microleakage in general with time even in non-loaded condition. In addition there is a time-dependent rate difference in leakage from internal chamber to the external milieu compared to from external milieu to internal chamber between two different abutments at various torque values. Future studies needed to determine the effect of this bidirectional microleakage on peri-implant tissues around zirconia abutments. Also this in-vitro study can be repeated under loading condition to 
determine differential effect of loading on bidirectional microleakage around zirconia abutments. 
Dedicated to my whole family 


\section{ACKNOWLEDGMENTS}

\section{In the name of Allah, the Beneficent, the Merciful}

All Gratitude and thankfulness to Allah, who gave me the strength and patience to get this work to light.

I would like to thank my advisor Dr. Binnaz Leblebicioglu for her tremendous effort, time and encouragement during my research. Without Dr. Binnaz this work was impossible to be done as present

I would like to thank Dr. Julie Holloway and Dr. Edwin McGlumphy for their encouragement, contribution and being members of my committee.

I would like to thank Dr William Johnston for his help doing the color difference analysis.

I would like to thank Michelle Carlton for her help doing the Micro-CT.

I would like to thank Jeffrey Galley for his help his help in LPS study.

I would like to thank Dr. Robert Seghi for supplying the metal holder.

I would like to thank Dr. Robert Rashid for his help in photography.

I would like to thank Astra Tech Dental for supporting my research project and supplying all the implant parts required for the research (Grant \# D-2009-27). 
I would like to thank my entire faculty in the Graduate Prosthodonics Educational Program, Dr. Ernest Svensson, Dr. Wayne Campagni, Dr. Julie Holloway, Dr. Alex Peregrina and Dr. Liza Knobloch.

I would like to thank my entire fellow residents and the entire staff.

I would like to thank my entire family for their help, support and encouragement not only during my residency but for all what they did through out my whole life. 


\section{VITA}

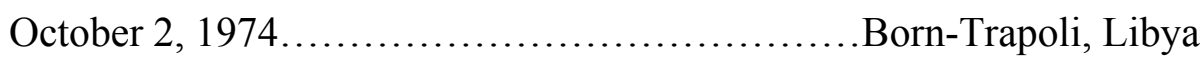

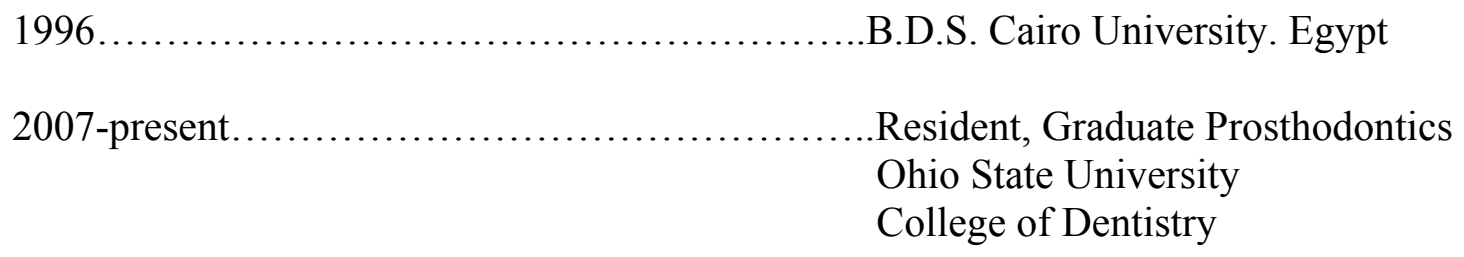

Fields of Study

Major Field: Dentistry

Specialty: Prosthodontics

\section{Publications}

Abdelhamed M, Carlton M, Holloway J, McGlumphy E, Leblebicioglu B. A comparison of Zirconia and Titanium abutments for microleakage. J. Dent. Res. 89B (Special issue) Abstract \# 137479, IADR 2010. 


\section{TABLE OF CONTENTS}

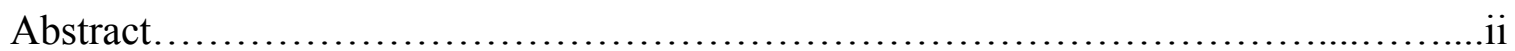

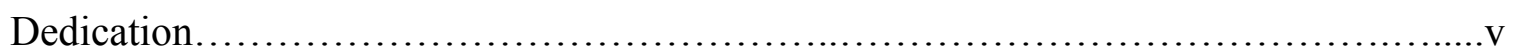

Acknowledgments......................................................... vi

Vita.....................................................................

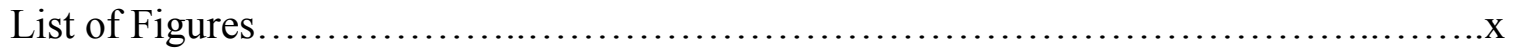

Chapters:

1. Introduction........................................................

2. Materials and Methods.................................................. 12

3. Results.......................................................... 19

4. Discussion......................................................... 36

References..............................................................44 


\section{LIST OF FIGURES}

Figure

\section{Page}

Figure 1- Flow Chart for Experimental Design..................................13

Figure 2-Micro-CT pictures presenting an example of studied details related to abutment-implant interface in zirconia abutment-implant apparatus-cross section.

Figure 3-Micro-CT pictures presenting an example of studied details related to abutment-implant interface in zirconia abutment-implant apparatus- longitudinal section. 24

Figure 4-Micro-CT pictures presenting an example of studied details related to abutment-implant interface in titanium abutment-implant apparatus-cross section. 25

Figure 5-Micro-CT pictures presenting an example of studied details related to abutment-implant interface in titanium abutment-implant apparatus- longitudinal section

Figure 6-3-D model structured from micro-CT pictures-Titanium abutment.

Figure 7-3-D model structured from micro-CT pictures -Zirconia abutment.

Figure 8-Radiographic picture for titanium abutment-implant apparatus 
Figure 9- Radiographic picture for zirconia abutment-implant apparatus.

Figure 10- LPS microleakage from implant chamber into external

milieu.

Figure 11- LPS microleakage from implant chamber into external

milieu

Figure 12- Toluidine dye penetration from external milieu into implant

chamber

Figure 13- Toluidine dye penetration from screw access hole into implant chamber

following 3 days incubation. ...

Figure 14- Toluidine dye penetration from screw access hole versus from implantabutment connection into implant chamber following 3 days incubation.

Figure 15- Toluidine dye penetration following several torquing/ anti-torquing.

Incubation time for this experiment was 2 weeks.

Figure 16- Toluidine dye penetration comparison between single torque vs multiple torques 


\section{CHAPTER 1}

\section{INTRODUCTION}

The introduction of dental implants as an alternative to conventional removable and fixed dental prostheses has had a significant impact on contemporary dentistry. High success rates for dental implant and implant supported prosthesis have been well

documented in the literature ${ }^{1-4}$. While dental implants are not prone to the effects of dental decay, the same microbes that are the causative factor in periodontal disease around teeth can affect the tissues around dental implants ${ }^{5}$. Although the related pathogenesis is not well understood, presence of a microgap between implant body and abutment at the alveolar level has been suspected ${ }^{6,7}$. Possible crevicular fluid leakage from peri-implant sulcus into the implant body from the microgap may create an ideal niche for bacterial growth ${ }^{8}$.

\section{Success Rate versus Survival Rate of Implant-Supported Dental Restorations}

Success rates and survival rates have separate definitions when referring to dental implants. Success rates generally include the criteria described by Alberktsson et al, in early 1980s which state that the implant is clinically immobile, peri-implant radiolucency does not exist, annual bone loss is less than $0.2 \mathrm{~mm}$ after first year of service and there are no signs of pain, infection or paraesthesia associated with the implant for 10 years $^{2}$. This classification has been modified in parallel to recent 
improvements in implant dentistry and $0.2 \mathrm{~mm}$ expected annual bone loss is no longer accepted ${ }^{9}$.

Survival rates define an osseointegrated dental implant still in function (present in the mouth). It does not include a description of peri-implant health. Most of the clinical investigations on success of dental implant-supported restorations are retrospective studies and report survival rates instead of actual success rates. Thus early and late complications affecting peri-implant tissues and related pathogenesis are not well documented ${ }^{10}$.

\section{Peri-implant Pathogenesis and role of microgap}

Microgap is defined as the microscopic space that exists between the implant body and abutment ${ }^{11,12}$. This gap is generally measured in microns meters and is located at the junction between the implant and implant abutment ${ }^{7}$. The microgap may act as a reservoir for bacteria, which can lead to release of bacterial byproducts and induction of an inflammatory reaction at both soft and hard tissue level ${ }^{13,14}$. The main mechanism proposed for microgap-related crestal bone loss is the role of this space as a trap for bacteria and thus, as a putative etiological factor for inflammatory reaction in the periimplant soft tissues ${ }^{15}$. The establishment of inflammatory cell infiltrates at the implantabutment junction, even around implant with meticulous plaque control and clinically healthy soft tissue, has recently been shown histologically in dog model by Ericson et al. ${ }^{16}$ In another dog model, the implant-abutment interface at the alveolar bone crest was associated with persistent peri-implant inflammation ${ }^{17}$. This second study was conducted to compare the distribution and amount of inflammatory cells adjacent to implant with a supra-crestal, crestal or sub-crestal implant-abutment interface ${ }^{17}$. Polymorphonuclear 
leukocytes or neutrophils accumulated at the greatest levels near or immediately coronal to the interface. However, peri-implant neutrophils increased progressively as the implant-abutment interface depth increased. Thus, the inflammatory cell accumulation below the original bone crest was significantly correlated with bone $\operatorname{loss}^{17}$. In a clinical study, Quirynen et al, suggested that the microorganisms detected from the inside of the implant three months after abutment connection may be the result of leakage at the implant-abutment interface or contamination during abutment connection ${ }^{6}$.

Several in vivo and in vitro study models have been developed to investigate the microgap-related microleakage problems. These models include Scanning Electron Microscopy (SEM), X-ray radiation, dye and/or bacterial penetration ${ }^{18}$.

Piattelli et al conducted an in vitro study to compare the size of microgap between screw-retained and cement-retained abutments using SEM. They found that an average gap size of 2-7 microns exists and, in the case of cement-retained abutments, the gap was filled with cement. The same group performed dye and bacterial penetration analyses using toludine blue and a culture of Pseudomonas aeruginosa as testing media and they found that leakage occurred in both systems, but it was less in cement-retained abutments $^{18}$. In a retrospective analysis of failed implants examined by SEM, O'Mahony et al reported that the implant transmucosal abutment interface (microgap) ranged from 22-40.5 microns ${ }^{19}$.

Serge et $\mathrm{al}^{20}$, evaluated the bidirectional microleakage in a locking taper system using a wide body implant ${ }^{1}$ with inoculation of a mixture of Actinobacillus actinomycetemcomitans and Streptococcus oralis. The results revealed that the locking taper system provided a hermetic seal, meaning that there was no leakage in either

\footnotetext{
${ }^{1}$ Bicon implant system
} 
direction ${ }^{20}$. Steinebrunner et al, performed a similar in vitro study and added loading conditions to the test ${ }^{21}$. The results revealed microleakage for different implant systems ${ }^{21}$.

Do Nascimento et al, compared the Fusobacterium nucleatum microleakage through a microgap using a single implant system with two types of abutments (premachined and casted abutment) ${ }^{22}$. They found that both systems had leakage. Jansen et al, compared thirteen different implant systems using Escherichia coli as the testing micro-organism ${ }^{15}$. Results showed that microbial leakage occurred in all systems although systems with internal connection showed less leakage than implants with external connection. Guindy et al. reported that bidirectional leakage occurred through the microgap and screw hole in titanium implant system ${ }^{23}$. Persson et al sampled the internal cavity of the 28 implants that were in function for 1-8 years, bacterial analysis revealed mostly anaerobic bacteria. ${ }^{24}$ Harder et al reported endotoxin leakage from the inoculated implant chamber to the outside using two different implant systems with a morse shape lock system and both implant systems demonstrated leakage ${ }^{25}$.

Toludine blue dye was also used to evaluate microleakage through the implantabutment interface by placing a small piece of absorbent filter paper that fits inside the implant well. Following the abutment connection and incubation of the implant-abutment assembly in the dye, the paper was retrieved and the existence of blue color change was an indication of leakage ${ }^{18}$.

Recent advances in molecular biology allow bacterial DNA analyses for very small samples and create a fast and reliable identification and quantification of microorganisms in oral cavity, greatly facilitating periodontal and peri-implant disease diagnosis and treatment outcome evaluation ${ }^{27}$. Similar techniques have been in use to 
detect bacterial contamination of dental implants during surgery and leakage through the microgap. DeAngelo et al, have used Polymerase Chain Reaction (PCR) assays to detect several bacteria within the newly forming peri-implant crevice and in the implant chamber following a one-stage surgical protocol ${ }^{28}$. It was found that $F$. nucleatum was the only pathogen that could be detected and followed through the first 12 weeks of healing ${ }^{28}$. Barbosa et al, evaluated bacterial leakage through the microgap in an in vitro study model by conventional bacterial culture and DNA Checkboard hybridization methods. It was concluded that the DNA Checkboard hybridization method is more sensitive than the conventional bacterial culture method and has the advantage of identification and quantification of bacteria associated with implant components and periimplant tissues ${ }^{29}$.

A more recent technique has been introduced to evaluate the microgap that exists between implant components by using monochromatic hard X-ray synchrotron radiation, which is a very intense electromagnetic (photon) radiation, emitted by high speed electrons close to the speed of light with the advantage of improved contrast and reduced artifacts ${ }^{30}$.

In summary, based on these in vitro and in vivo study models, the microgap and related bidirectional leakage from external milieu into the implant chamber and from internal implant chamber to the external milieu exists. In addition, this leakage has a potential role in bacterial growth and peri-implant pathogenesis.

\section{One-piece versus Two-piece Dental Implant Systems and Various Abutments}

Currently, there are two implant restorative options in relation to implant bodyabutment apparatus; One-piece dental implants are designed so that the standard 
abutment is fabricated together with implant body as single piece, and two-piece dental implants may have a standard or custom-made abutment fabricated separate from the implant body ${ }^{31}$. Two-piece implants are mostly used due to availability of custom-made angled abutments while one piece implants are primarily indicated for specific small diameter cases.

Two-piece dental implants can be placed by using two different surgical techniques: two-stage (submerged) implant placement surgery or one-stage (nonsubmerged) implant placement surgery. In these surgical techniques, implants with no polished collar are placed with the most coronal part of the implant body being flush with the alveolar crestal bone. Thus, the final implant-abutment connection with the possible microgap is located at the bone level for this type of implant independent of surgical technique. ${ }^{32}$ In addition, most of the companies providing implants with a minimal polished collar recommend submerging the polished collar into the alveolar bone especially in esthetic regions. Thus the microgap will be either at the alveolar crest or below the alveolar crest.

Peri-implant crestal bone changes differ significantly and is dependent on a rough/smooth implant border in one-piece implants and on the location of the interface (microgap) between the implant and the abutment in the two-piece configuration (regardless the size of the microgap) as shown in dog model by Hermann ${ }^{33}$.

An average of $2 \mathrm{~mm}$ of crestal bone loss is reported around two-piece implants placed using a two-stage (submerged) surgical technique and this finding was correlated to the microgap location in relation to the alveolar crest $^{2}$. While with one-piece implant design, placed with one stage (non-submerged) surgery and with the rough/smooth border 
located at the bone crest level, there was minimal or no bone resorption following a similar healing period ${ }^{34}$.

The microgap location in relation to the alveolar crest was further studied in a dog model $^{35}$. It was reported that the severity of crestal bone resorption was strongly related to the position of the micro-gap in relation to the bone crest, the most severe crestal bone loss and peri-implant inflammation occurred when the gap located $1 \mathrm{~mm}$ below the crest. Less severe bone loss and inflammation occurred when the micro-gap was located at the bone crest and the least bone resorption and inflammation occurred when the micro-gap located $1 \mathrm{~mm}$ above the crest ${ }^{35}$. It was also found that crestal bone resorption does not occur as long as the implant is submerged but is initiated when the implant is exposed to the oral environment ${ }^{36}$. In addition, a progressing type of crestal bone loss was noted around two-piece implants with an expected loss of $1.5 \mathrm{~mm}$ in the first year of loading and $0.1 \mathrm{~mm}$ in the following years ${ }^{1}$.

Several implant companies are currently searching for a better implant design to prevent microleakage related to peri-implant complications. One such implant modification is to provide a polished collar which positions the microgap location above the alveolar crest with less bacterial adhesion on polished surface compared to porous titanium surface ${ }^{37}$. However, this design may not be as well accepted in esthetic regions due to metal collar showing through the gingiva.

The locking taper abutment includes a post part which is inserted into a well provided in the implant body with an enlarging diameter from bottom to top and it is retained to the implant by means of friction (tapped in) while in the morse taper abutment it is retained by a screw. The locking taper abutment design has been introduced by 
many companies to reduce the microleakage. The effectiveness of the seal provided by a locking taper was investigated by Dibart et al in an in vitro model ${ }^{38}$; results showed that the seal was hermetic (i.e. completely sealed) with regard to bacterial invasion in both directions. However, Jansen et al ${ }^{15}$ studied several implant-abutment interfaces in relation to microbial penetration in vitro. They found that even morse taper implant systems cannot safely prevent microbial leakage and bacterial colonization of the inner part of the implant. In another in vitro study, different conical implant-abutment connections regardless of their tapped-in or screwed-in connection showed bacterial leakage in an unloaded condition ${ }^{11}$.

"Platform switching" is defined as the process of using a smaller diameter abutment on a larger diameter implant platform. This type of connection shifts the margin of the microgap inward toward the central axis of the implant resulting in a possible shift of the inflammatory cell infiltrate to the central axis of the implant and away from the adjacent crestal bone with decrease in crestal bone resorption ${ }^{35}$. In a clinical study, Hurzeler showed that platform switching reduced crestal bone loss and preserved periimplant bone level ${ }^{39}$. They concluded that the reduction of the abutment $0.45 \mathrm{~mm}$ on each side (5 mm implant/ $4.1 \mathrm{~mm}$ abutment) seems sufficient to avoid peri-implant bone loss.

The "Laser lock" system is a series of precision 8-12 micron grooves on the collar of dental implant to have a connective tissue attachment at the crest. Nevins et al, in a human study using this laser lock system, found that micro-channels encouraged bone and connective tissue attachment and prevented apical growth of epithelium. ${ }^{40}$

For implants with screw-retained abutment (two-piece implant), the bacteria can penetrate inside the internal cavity of the implant as a consequence of leakage through 
implant/abutment interface. An alternative to a screw-retained abutment is to use implants that can receive cemented abutments which are reported to offer better results related to fluid and bacterial permeability compared to screw-retained abutments ${ }^{18}$. The use of different sealing materials (adhesive, silicone O-ring washer, wax, silicone hermetic washer, chlorhexidine-thymol varnish, a seal washer and $2 \%$ chlorhexidine solution) at the implant-abutment interface to prevent the bacterial penetration was investigated in an in vitro model and most of these materials were not able to prevent contamination over 63 days. In that study, the implants showed bacterial contamination regardless of their external or internal hexagonal configuration ${ }^{41}$. A fluid-tight connection was also presented by modification of the implant-abutment interface with special silicone washer that clearly reduced bacterial penetration as compared to the standard implant-abutment interface, although these specimens were not subjected to cyclic functional loads. ${ }^{15}$

Proff et al, tested the ability of gutta percha to provide adequate seal at the microgap against bacterial penetration by using an in vitro model and reported that bacterial leakage occurred after $24 \mathrm{hrs}^{42}$. In a clinical study by Groenendijk et al, the use of $0.2 \%$ chlorohexidine solution was compared to saline as a control. Implants that were inoculated with chlorhexidine at second stage surgery resulted in lower numbers of bacteria compared to ones inoculated with saline only ${ }^{43}$. In an in vitro study performed by Besimo et al, sealing of the gap with chlorhexidine-containing varnish Cervitec ${ }^{\circledR}$ maintained the implant seal and prevented bacterial penetration into the test specimens for up to 11 weeks under unloaded conditions. ${ }^{44}$ 


\section{Closing Torque Values for Abutment placement and Microgap}

Microleakage at the implant/abutment interface has been shown to occur in all implant systems with variability between systems, study model and closing torque value. In general, as the closing torque increases from $10 \mathrm{Ncm}$ to $20 \mathrm{Ncm}$ to manufacturer's recommended closing torque, microleakage decreases significantly ${ }^{26}$. However, it is important to note that repeated tightening of the abutment screw has been shown to result in a progressive decrease in removal torque. ${ }^{45}$ Nascimento et al, investigated the effect of repeated tightening of abutment screw on leakage of Streptococcus mutans through the implant pre-machined abutment interface and reported that bacterial leakage occurs between implants and abutments even under the unloaded condition and the leakage is higher when the abutment screw is tightened and loosened repeatedly ${ }^{46}$.

\section{$\underline{\text { Zirconia Abutment and Microleakage }}$}

In light of increasing esthetic demands, zirconia abutments have become preferred as the abutment of choice especially in patients with a thin soft tissue biotype. In addition, these abutments may have the potential requirement to be secured with closing torque values lower than what manufacturer recommends due to the possible risk of abutment fracture. Currently, there is no data available on possible microleakage problems related to zirconia abutments.

Thus, the purpose of the study was to investigate microleakage through the implant-abutment interface using two different abutments of the same design (titanium abutment and zirconia abutment) at two different torque levels for varying time periods. 
The Null hypothesis was that there is no difference in the microleakage between titanium and zirconia abutments at different closing torque values and at different time intervals in an in vitro non-loading condition.

\section{Specific aims were:}

1- To determine whether there is a detectable microgap at the implant-abutment interface for two different implant-abutment materials combinations.

2- To determine presence of microleakage from the internal implant chamber to external milieu following E.coli LPS inoculation for two different implant-abutment materials combinations.

3- To determine presence of microleakage from external milieu into implant chamber following incubation of two different implant-abutment materials combinations in toluidine blue dye.

4- To determine whether bidirectional microleakage is dependent on closing torque values.

5- To determine whether bidirectional microleakage is time dependent.

The clinical significance of this study is to better understand whether there is any difference between zirconia and titanium abutments in relation to microgap leakage. These results would be important in the soft and hard tissue stability of zirconia abutment-supported implant crowns, particularly in areas of thin soft tissue biotype. 


\section{CHAPTER 2}

\section{MATERIALS AND METHODS}

Thirty-two dental implants ${ }^{2}$, sixteen titanium abutments ${ }^{3}$ and sixteen zirconia abutments ${ }^{4}$ were used in this experiment. Implants were either fixed in an acrylic block or mounted into a sterilized holder. Abutments were connected to the implants and torqued using a torque wrench $^{5}$ to two different closing torque values $(25 \mathrm{Ncm}$ and $15 \mathrm{Ncm})$. These two values were selected based on manufacturer's recommended torque values and average values reported in the literature for hand torquing. ${ }^{47}$

The study design is presented in Figure 1.

2 Osseospeed"4.5X13mm implants with a $\mathrm{TiO}_{2}$ blasted, fluoride -modified surface, MicroThread neck, Conical Seal Design Connection, Internal double hexagon and Internal thread M2 ( Lot \# 67202 Astra Tech Dental , Mölndal, Sweden ) 3 TiDesign 4.5/5 Ǿ5.5,3mm including Abutment Screw Design 4.5/5-M2(Ti-alloy) (Lot \# 67840 Astra Tech Dental, Mölndal, Sweden)

4 ZirDesign 4.5/5 Øீ5.5,3mm including Abutment Screw Design 4.5/5-M2(Ti-alloy) (Lot \# 66078 Astra Tech Dental , Mölndal, Sweden)

${ }^{5}$ Astra Torque Wrench 


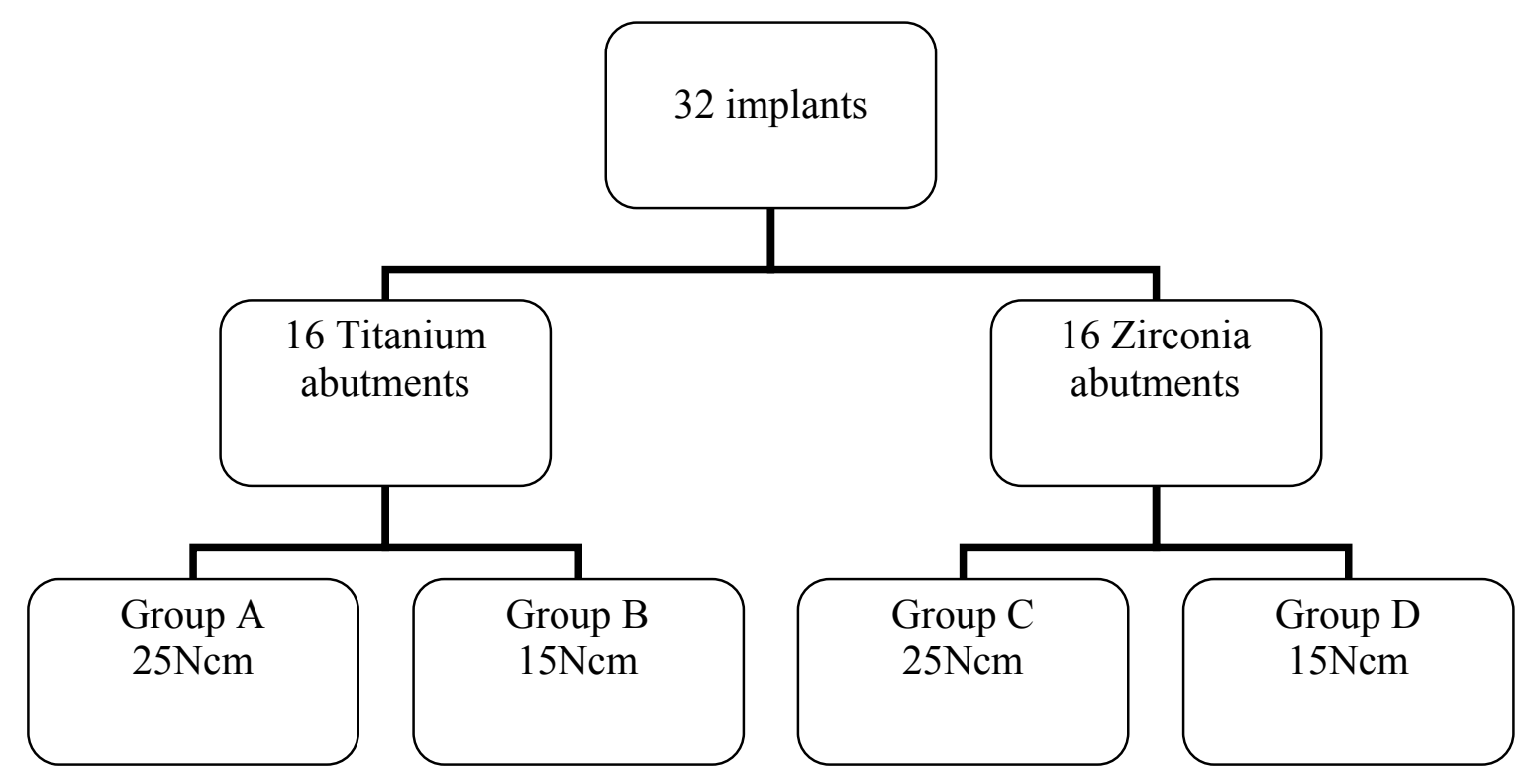

Figure 1: Flow Chart for Experimental Design 
Implants were divided into four experimental groups: Group A $(\mathrm{N}=8)$ in which titanium abutments were torqued to $25 \mathrm{Ncm}$, Group $\mathrm{B}(\mathrm{N}=8)$ in which titanium abutments were torqued to $15 \mathrm{Ncm}$, Group $\mathrm{C}(\mathrm{N}=8)$ in which zirconia abutments were torqued to $25 \mathrm{Ncm}$, and Group $\mathrm{D}(\mathrm{N}=8)$ in which zirconia abutments were torqued to $15 \mathrm{Ncm}$. A Limulus Amebocyte Lysate (LAL) test was conducted first to ascertain the possibility of contamination of individually packed dental implant parts with possible LPS from external milieu and then LPS microleakage from inoculated implant internal chamber. Following completion of LAL experiment, the same implants were used for a toluidine dye penetration experiment after rinsing and air drying of all parts for 48 hours. Micro-Computed Tomography (micro-CT) analysis was conducted prior to the dye penetration experiment to explore the implant-abutment connection for possible gaps. In addition, a dye penetration experiment was repeated with ten implants (five titanium abutments and five zirconia abutments) which were tightened and untightened 10 times to determine whether repeated torquing would affect the severity of microleakage. Finally, dye penetration through the screw entrance hole was evaluted on ten implants (five of each abutment material).

\section{RADIOGRAPHIC AND MICRO-COMPUTED TOMOGRAPHY ANALYSIS TO DETERMINE A GAP AT IMPLANT-ABUTMENT CONNECTION}

The implant/abutment interfaces were scanned in a SIEMENS Inveon ${ }^{\circledR 6}$ micro CT at a resolution of 9.7 microns. The acquisition was a full $360^{\circ}$ scan at maximum power and filtration (120KV and $1.5 \mathrm{~mm} \mathrm{AL}$, respectively). This was done to accommodate for the beam hardening artifact due to the rather dense subject material. The manufacturer's own

\footnotetext{
${ }^{6}$ Siemens Medical Solutions USA Inc .PA. USA
} 
software, Inveon Research work place ${ }^{\circledR 7}$ was used to visualize the data of each assembly in 3-dimensions to confirm or deny the presence of a gap within the resolution capabilities of the scanner. Similarly, high resolution radiographs were obtained to determine presence or absence of a microgap at the implant/abutment interface.

\section{IN VITRO LPS MICROLEAKAGE STUDY TO DETERMINE LEAKAGE FROM IMPLANT CHAMBER INTO EXTERNAL MILIEU}

Each implant body and abutment was unpacked under a ventilation hood using sterile technique. $0.5 \mu 1$ of 1500 EU E. coli Lipopolysacharide ${ }^{8}$ (LPS) was placed into the internal implant chamber using sterile pipette tips. The implant was then placed into a sterile holder and abutment was torqued with a calibrated torque wrench to $25 \mathrm{Ncm}$ or $15 \mathrm{Ncm}$. The implant-abutment combination was examined for any fluid leakage during the torquing procedure and then placed into sterile test tubes containing sterile Pyrotell water ${ }^{9}$ and incubated in $37^{\circ} \mathrm{C}$ incubator. $220 \mu 1$ of supernatant liquid was taken from these tubes at 5 minutes, 25 hours, and 195 hours. The supernatant was diluted in half with sterile water a number of times to create a range of dilutions. The Limulus Amebocyte Lysate (LAL) test ${ }^{10}$ was run on the dilutions. Reconstituted Pyrotell, with a sensitivity of $0.03 \mathrm{EU} / \mathrm{mL}$, was added at a 1:1 (v: v) ratio with each dilution. Each tube was gently mixed, and then placed in a $37^{\circ} \mathrm{C}$ water bath for $1 \mathrm{hr}$. After $1 \mathrm{hr}$, the tubes were removed and swiftly inverted. If a clot had formed and did not break upon inversion, the test was positive. If a clot had not formed or broke upon inversion, the test was negative. In order to calculate the amount of LPS in each sample, the ratio of the last

\footnotetext{
${ }^{7}$ Siemens Medical Solutions USA Inc .PA. USA

${ }^{8}$ Sigma Aldrich. Catalog number L2630, Lot Number 118 K4052

9 Associates of Cape Cod, MA,USA

${ }^{10}$ Associates of Cape Cod, MA,USA
} 
positive sample was inverted and multiplied by the sensitivity of the Pyrotell (i.e. dilution $1: 4=4 \times 0.03 \mathrm{EU} / \mathrm{mL}=0.12 \mathrm{EU} / \mathrm{mL})$

\section{IN VITRO TOLUIDINE DYE MICROLEAKAGE STUDY TO DETERMINE LEAKAGE FROM EXTERNAL MILIEU INTO IMPLANT CHAMBER}

Implants were mounted in acrylic blocks made of OrthoJet ${ }^{11}$ polymethylmethacrylate resin. A $1.5 \mathrm{~mm}$ diameter tissue punch ${ }^{12}$ was used to cut absorbent filter paper $^{13}$ into round specimens to be placed inside of the implant. Two specimens of the filter paper were placed inside of the implant and then the abutment was connected. Implant was held using a metal device and the abutment was torqued to the assigned torque value for that specific group. The implant/abutment assemblies were placed in a sterile, non-pyrogenic test tube. ${ }^{14}$ Toluidine blue dye was placed first into screw access hole and then the remaining of implant/abutment apparatus was lowered into the dye. In some experiments, the screw access hole was sealed with a composite plug to differentiate microleakage from microgap and from screw access hole. The test tubes were incubated in a $37^{\circ} \mathrm{C}$ water bath for varying lengths of time: three days, one week, two weeks, and three weeks. The abutment screws were then untightened and tightened ten times, and the dye application test was repeated using a two week incubation time. At the end of each test period, the implant-abutment assemblies were removed from the test tube and washed under running water. The screw access hole was rinsed with distilled water using a disposable syringe. All implant/abutment assemblies were left to dry at room temperature for 2 days. To evaluate the presence and degree of dye penetration, the abutments were

\footnotetext{
11 (LANG) orthodontic clear acrylic resin

12 Uni-Punch, Disposable Biopsy Punch, Premier Medical Products

${ }^{13}$ Periopaper "gingival fluid collection strips ORAFLOW

${ }^{14} 15 \mathrm{ml}$ polystyrene conical tube ,BD Falcon
} 
removed and filter paper dots were retrieved from the inside of the implants. The paper dots then mounted on a glass slab ${ }^{15}$ and covered with glass cover. ${ }^{16}$

\section{COLOR CHANGE MEASUEMENT:}

Color change of the paper filter specimens (e.g. the difference between dark blue to bright white) was determined using a Colorimeter. ${ }^{17}$ The meter combines advanced electronic and optical technology and measures both incident and reflected light through high-sensitivity silicon photocells. Light source is a pulsed xenon arc (PXA) lamp. For this study, two paper filter dots prepared from Periostrip ${ }^{\circledR}$ and mounted on a glass slab were used as a base line. The test is considered positive if a color change was detected by the colorimeter reading and/or observed by eye. $\Delta \mathrm{E}$ is the change in color from baseline and was calculated using the following formula:

$$
\Delta \mathrm{E}^{*} \mathrm{ab}=\left[\left(\Delta \mathrm{L}^{*}\right)^{2}+\left(\Delta \mathrm{a}^{*}\right)^{2}+\left(\Delta \mathrm{b}^{*}\right)^{2}\right]^{1 / 2} \quad 48
$$

This equation is called the CIE (Commission Internationale de l'Eclairage, 1976) $1 * a * b *$

color difference formula, where:

$$
\begin{aligned}
& \mathrm{E}=\text { color difference } \\
& \mathrm{L}=\text { lightness variable (describes the achromatic characteristics of color) } \\
& \mathrm{a}^{*} \text { and } \mathrm{b}^{*}=\text { Coordinates describing chromatic characteristics of color }
\end{aligned}
$$

The colorimeter was calibrated according to the manufacturer's recommendation using a standard white reflecting plate. The baseline measurement was followed by the sample

\footnotetext{
${ }^{15}$ MEDI-LAB Microscopic slides (General Medical Corporation

${ }^{16}$ Fisher brand, Microscopic glass cover, Fisher Scientific
${ }^{17}$ Minolta Chroma Meter CR 221-b Japan
} 
measurements and the color difference was calculated using the CIE $1976\left(1 * \mathrm{a}^{*} \mathrm{~b}^{*}\right)$ color difference formula.

\section{STATISTICAL ANALYSES:}

GraphPad Sigma version 5 software $^{18}$ was used for the statistical analyses. A two-way Analysis of Variance (ANOVA) (also known as factorial ANOVA) with Benferroni post test was used to analyze time and abutment type/torque value interaction. A one-way ANOVA followed by Benferroni's Multiple Comparison test was used to analyze the effect of microleakage through screw access hole and to analyze the effect of repeated of tightening on the microleakage. The level of statistical significance was set at alpha $=0.05$.

\footnotetext{
${ }^{18}$ GraphPad Software, Inc. LaJolla CA, USA
} 


\section{CHAPTER 3}

\section{RESULTS}

\section{RADIOGRAPHIC AND MICRO-COMPUTED TOMOGRAPHY ANALYSES}

The three dimensional data obtained using Micro-Computed Tomography (microCT) were used to determine presence or absence of a gap at the implant/abutment interface (Figures 2, 3, 4 and5). The resolution of this method is 9.7 microns. The data acquisition was repeated three times for both zirconia and titanium abutments with and without the inserted filter paper dots into implant chamber to determine if the filter paper interfered with complete seating of the abutment into the implant. There was no detectable separation at the implant/abutment interface when filter paper dots were present at the bottom of the abutment screw hole. A three-dimensional construct was also produced to better examine the connection (Figure 6 and 7). Again, there was no detectable separation between implant and abutment surfaces for either zirconia or titanium abutments.

Due to the density difference between zirconia and titanium abutments, a high resolution radiographic analysis was included to confirm the micro-CT results (Figures 8 and 9). There was no detectable gap between implant-abutment surfaces at the recommended torque values. 


\section{IN VITRO LPS MICROLEAKAGE STUDY TO DETERMINE LEAKAGE FROM IMPLANT CHAMBER INTO EXTERNAL MILIEU}

The E.coli LPS leakage from the implant chamber into the external milieu was studied using the LAL test as described in Chapter 2. A time dependent increase in leaking LPS concentration was generally observed independent of abutment type and torque value $(\mathrm{P}=0.006$ for interaction, $\mathrm{P}=0.0027$ for time effect, and $\mathrm{P}=0.134$ for abutment type/torque value effect) (Figure 5). At the 5 minute incubation time period, LPS concentration within supernatant was $0.097 \pm 0.02 \mathrm{EU} / \mathrm{ml}, 0.06 \pm 0 \mathrm{EU} / \mathrm{ml}$ and $0.12 \pm 0$ $\mathrm{EU} / \mathrm{ml}, 0.037 \pm 0.01 \mathrm{EU} / \mathrm{ml}$ for titanium abutments at closing torque values of $25 \mathrm{Ncm}, 15$ $\mathrm{Ncm}$ and zirconia abutments at closing torque values of $25 \mathrm{Ncm}$, and $15 \mathrm{Ncm}$, respectively. These concentrations representing leakage into external milieu increased to $0.18 \pm 0.06 \mathrm{EU} / \mathrm{ml}, 0.075 \pm 0.04 \mathrm{EU} / \mathrm{ml}$ and $0.135 \pm 0.11 \mathrm{EU} / \mathrm{ml}, 0.36 \pm 0.12 \mathrm{EU} / \mathrm{ml}$ at $195 \mathrm{hrs}$ for the same abutment/torque value groups, respectively. However, the only statistically significant difference in LPS concentration was detected in the Zirconia abutment/15 Ncm torque group, between $5 \mathrm{~min}$. and $195 \mathrm{hrs}$ incubation times $(\mathrm{P}<0.001)$ (Figure 10).

LPS microleakage from the implant chamber into external milieu was also studied by comparing leakage observed in test samples (e.g. implants inoculated with E.coli LPS) to negative controls (e.g. implants with no E.coli LPS inoculation) (Figure 11). A similar, but more statistically significant increase in LPS microleakage with time was observed for each abutment type despite different torque values $(\mathrm{P}=0.0001$ for interaction, $\mathrm{P}<0.0001$ for time effect, and $\mathrm{P}=0.0024$ for abutment type/torque value effect). Baseline readings (ratios calculated for the 5 minute time period) were very similar between all groups $[0.8 \pm 0.18 ; 1 \pm 0 ; 1 \pm 0 ; 1.25 \pm 0.25$, respectively). Ratios 
calculated for the 195 hour time period were $6 \pm 2 ; 2.5 \pm 1.5 ; 2.25 \pm 1.75 ; 12 \pm 4$ for those same groups, respectively. Statistically significant increases were detected within titanium abutment group with closing torque values of $25 \mathrm{Ncm}(\mathrm{P}<0.01)$ and the zirconia abutment group with a closing torque value of $15 \mathrm{Ncm}(\mathrm{P}<0.001)$ (Figure 11).

\section{IN VITRO TOLUIDINE DYE MICROLEAKAGE STUDY TO DETERMINE LEAKAGE FROM EXTERNAL MILIEU INTO IMPLANT CHAMBER}

Toluidine dye penetration experiments were conducted to detect a time dependent leakage from the external milieu into the implant chamber for different abutment types with various closing torque values (Figure 12). Leakage through the screw access hole as compared to the implant/abutment combination was also investigated (Figures 13 and 14). Finally, the effect of repeated tightening and untightening upon the leakage from external milieu into implant chamber was studied (Figure 15 and 16).

Toluidine dye penetration experiments revealed that there was no statistically significant time effect on the microleakage from the external milieu into the internal chamber independent of abutment type and closing torque value $(\mathrm{P}=0.983$ for interaction, $\mathrm{P}=0.631$ for time effect, $\mathrm{P}=0.299$ for abutment type/torque values effect) (Figure 12). Mean $\Delta \mathrm{E}$ values were similar at two weeks compared to three days for titanium abutments with closing torque values at $25 \mathrm{Ncm}$ and $15 \mathrm{Ncm}$ and, for zirconia abutment with closing torque value at $25 \mathrm{Ncm}$ and $15 \mathrm{Ncm}$ groups ( $7.4 \pm 2.5$ vs. $8.5 \pm 0.74$ for titanium abutments torqued at $25 \mathrm{Ncm} ; 10 \pm 3$ vs. $10.4 \pm 1.4$ for titanium abutments torqued at $15 \mathrm{Ncm}$ and, $7 \pm 0.8$ vs. $8.8 \pm 0.2$ for zirconia abutments torqued at $25 \mathrm{Ncm}$; $8 \pm 1.5$ vs. $9.2 \pm 1.3$ for zirconia abutments torqued at $15 \mathrm{Ncm}$, respectively). There was an 
increase with time for titanium abutments. However, there was no statistically significant differences between these mean values $(\mathrm{P}>0.05)$ (Figure 12).

A second set of experiments was conducted to determine whether the screw access hole plays an important role in microleakage from the external milieu into the implant chamber, as compared to the implant/abutment interface itself (Figure 13). $20 \mu 1$ of toluidine blue dye was placed into the screw access hole after the abutment was torqued in place. All implant/abutment assemblies were placed in distilled water up to the implant/abutment connection and incubated at $37^{\circ} \mathrm{C}$ for 3 days. There was no statistically significant difference in microleakage through screw access hole for different abutment types at different closing torque values incubated for 3 days $(\mathrm{P}>0.05)$ (Figure 13). Interestingly, when mean $\Delta \mathrm{E}$ values for the 3 day microleakage from screw access hole experiment were compared to data for 3 days microleakage from implant/abutment interface, they were very similar. Mean $\Delta \mathrm{E}$ values were $7.36 \pm 0.9 ; 10.7 \pm 1.8 ; 9.46 \pm 0.4$; 12.2 \pm 2.3 for titanium abutments with closing torque values of $25 \mathrm{Ncm}$ and $15 \mathrm{Ncm}$ and, zirconia abutments with closing torque values of $25 \mathrm{Ncm}$ and $15 \mathrm{Ncm}$ for microleakage from screw access hole experiment, respectively. Similar values for microleakage from implant/abutment interface experiment with the screw access hole sealed with a plug were found $(8.46 \pm 0.7,10.4 \pm 1.4,8.76 \pm 0.1$ and $9.2 \pm 1.3$, respectively) (Figure 14).

Finally, an experiment was performed to determine whether repeated tightening and untightening would affect microleakage from the external milieu into the implant chamber (Figure 15). The incubation time for this experiment was chosen as two weeks, since more variations in microleakage were detected at the two week time interval in other parts of this study (Figure 12). Mean $\Delta \mathrm{E}$ values were higher in titanium groups 
compared to zirconia groups independent of closing torque value $(16.8 \pm 0.8,16.5 \pm 4.7$, $7.4 \pm 0.6$ and $10.8 \pm 0.3$, respectively). However, this difference was not statistically significant $(\mathrm{P}>0.05)$. Figure 16 presents microleakage data from single torque versus multiple torques/antitorques at two weeks observation time. There was an increase in microleakage from external milieu into implant chamber when abutment torqued/antitorqued several times compared to single torque ( $16.8 \pm 0.8$ vs $7.4 \pm 2.5$ for Titanium abutments with closing torque values of $25 \mathrm{Ncm}, 16.5 \pm 4.7 \mathrm{vs} 10 \pm 3$ for Titanium abutments with closing torque values of $15 \mathrm{Ncm}, 7.4 \pm 0.6$ vs $7 \pm 0.8$ for Zirconia abutments with closing torque values of $25 \mathrm{Ncm}$ and $10.8 \pm 0.3$ vs $8 \pm 1.5$ for Zirconia abutments with closing torque values of $15 \mathrm{Ncm}$, respectively). However this difference was statistically significant only for Titanium groups. $(\mathrm{P}<0.01)$. 


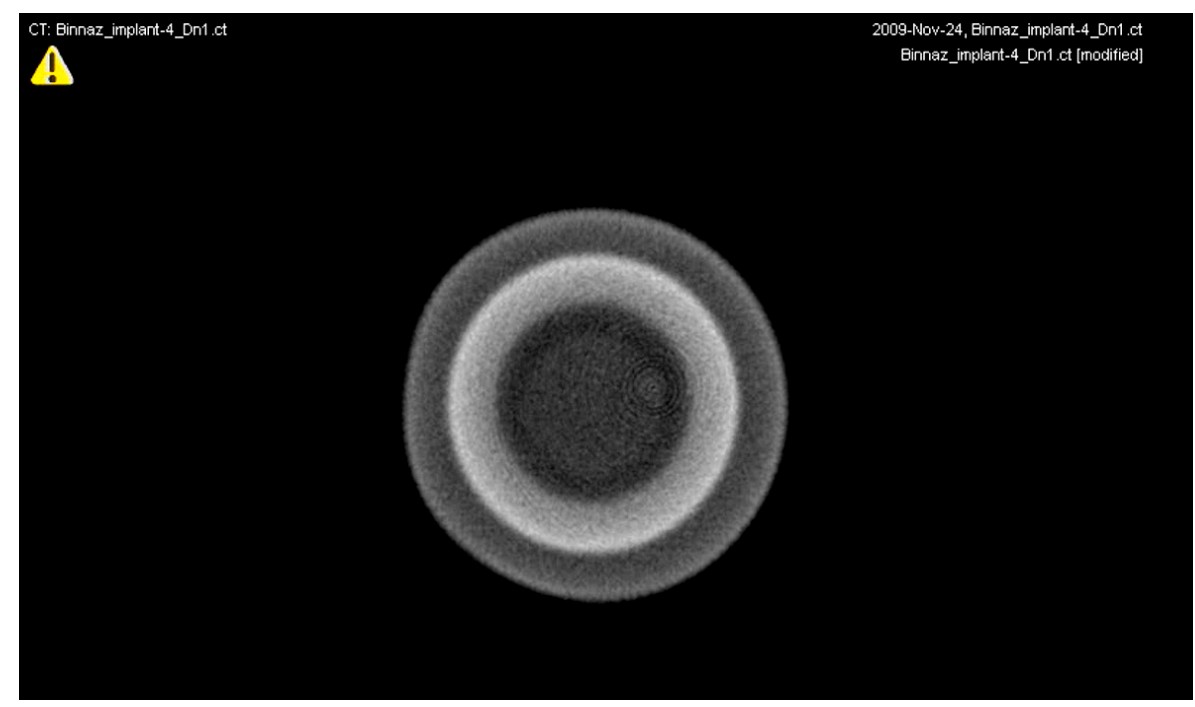

Figure 2: Micro-CT picture presenting an example of studied details related to abutmentimplant interface in zirconia abutment-implant apparatus-Cross section

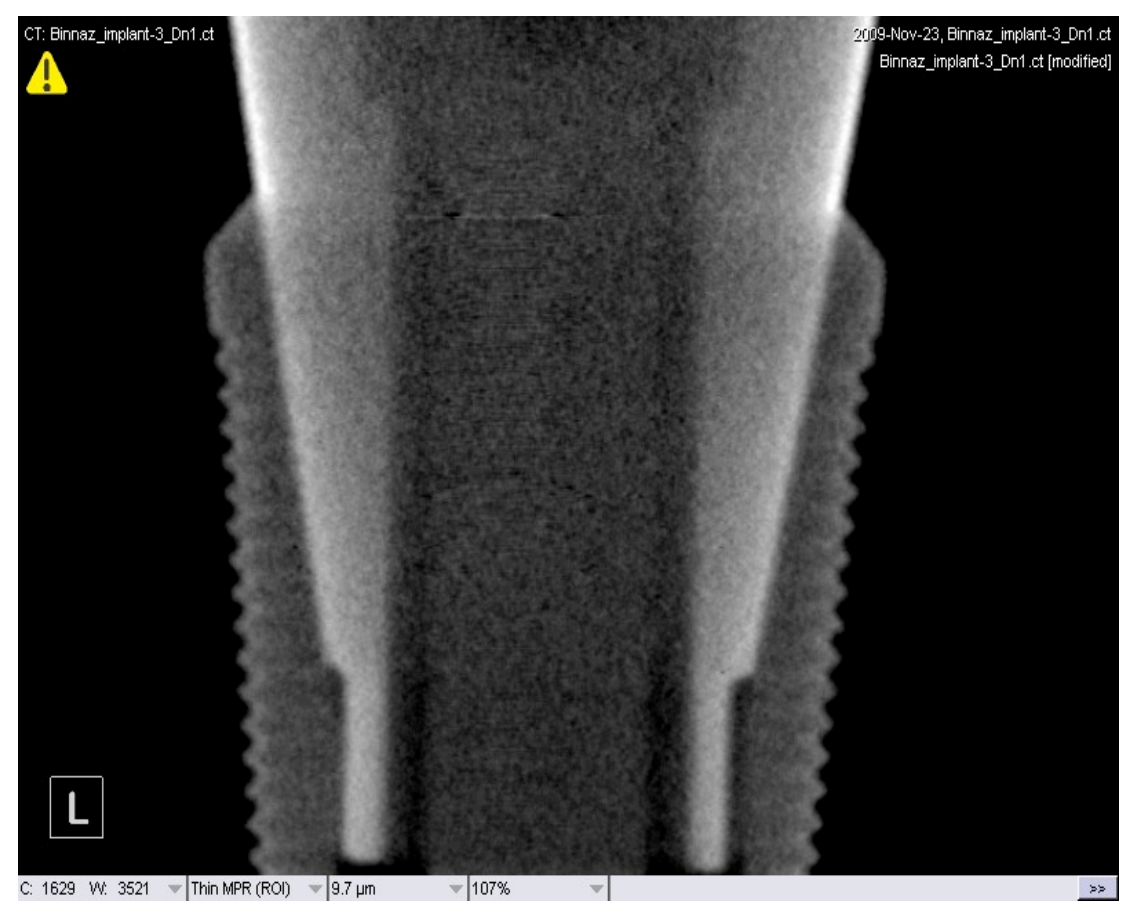

Figure 3: Micro-CT picture presenting an example of studied details related to abutmentimplant interface in zirconia abutment-implant apparatus-Longitudinal section 


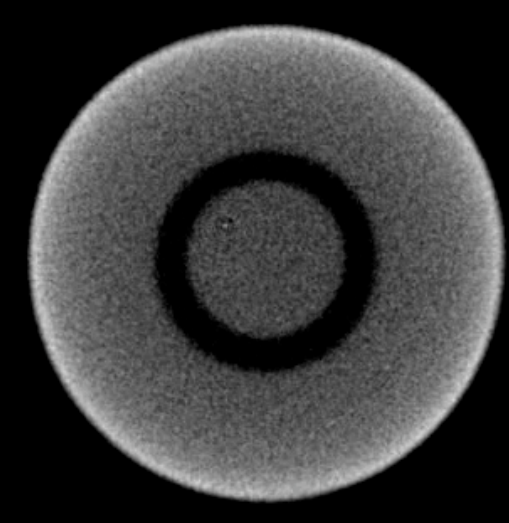

Figure 4: Micro-CT picture presenting an example of studied details related to abutmentimplant interface in titanium abutment-implant apparatus-Cross section

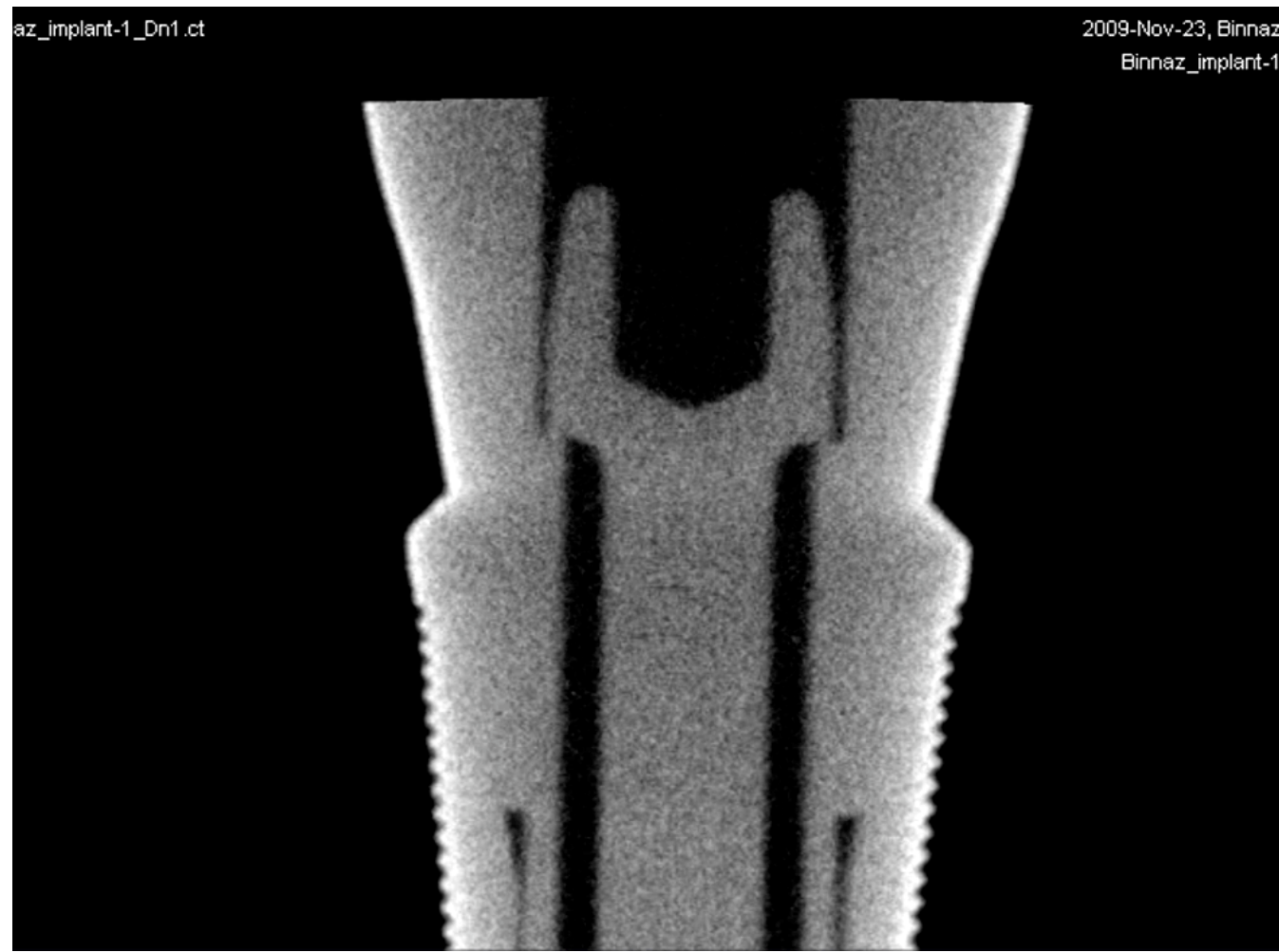

Figure 5: Micro-CT picture presenting an example of studied details related to abutmentimplant interface in titanium abutment-implant apparatus-Longitudinal section 


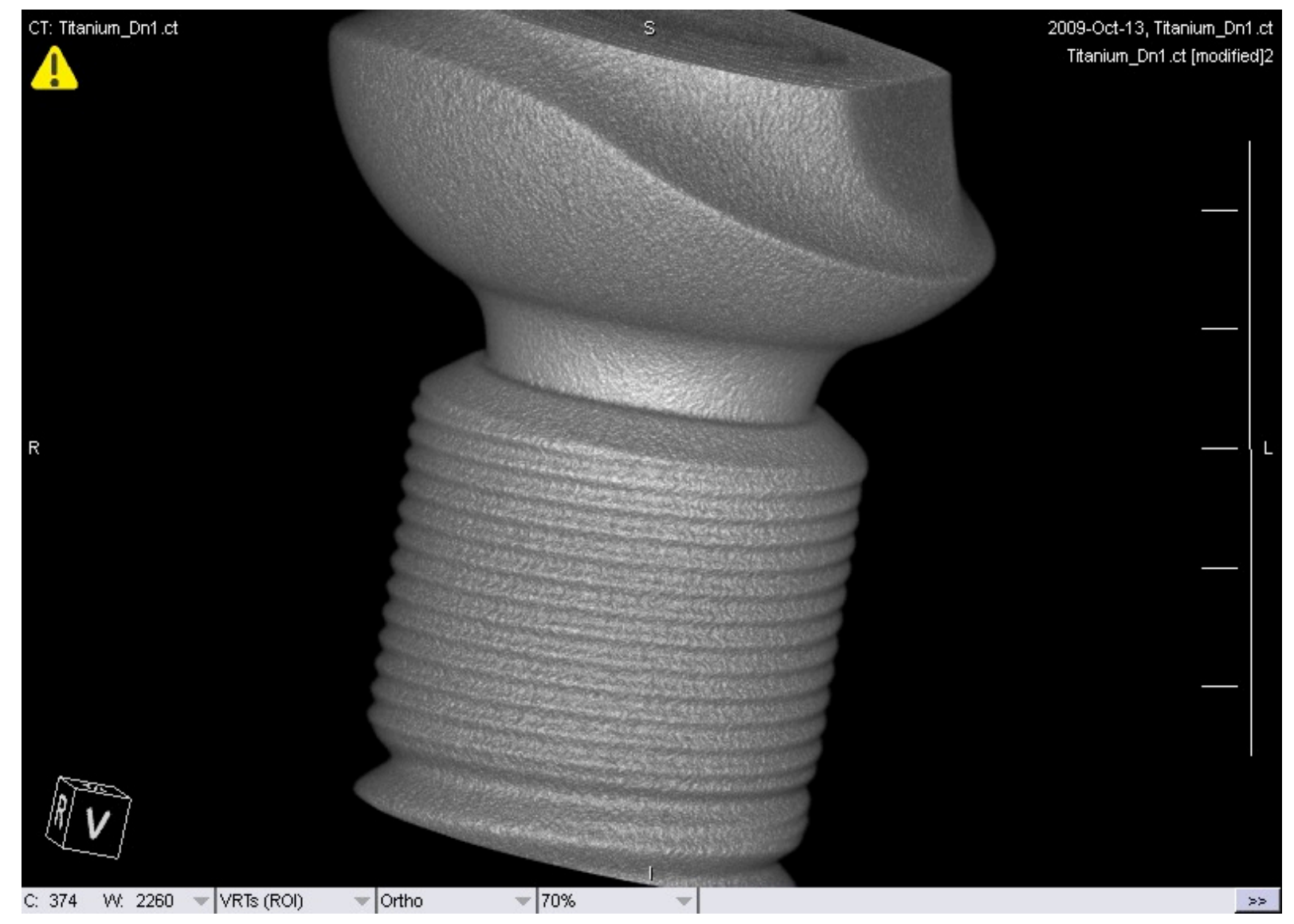

Figure 6: 3-D model structured from micro-CT pictures-Titanium abutment 


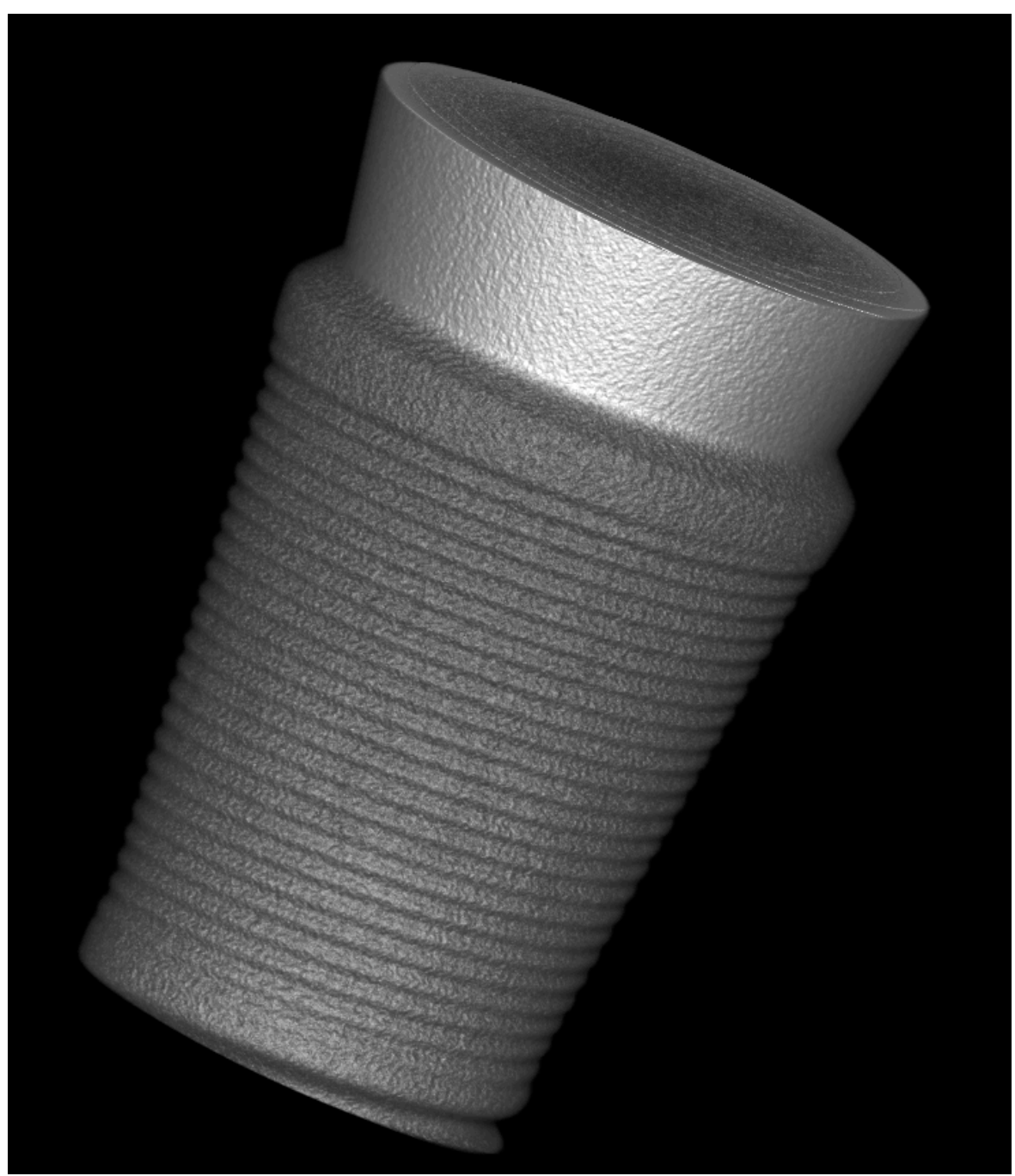

Figure 7: 3-D model structured from micro-CT pictures-Zirconia abutment 


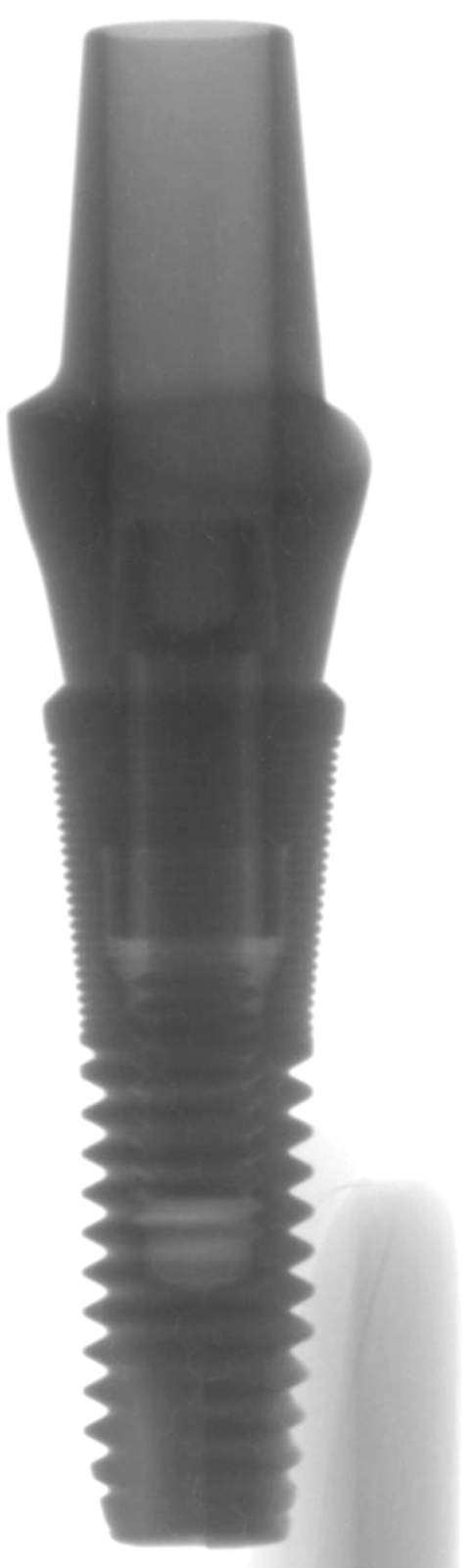

Figure 8: Radiographic picture for titanium abutment-implant apparatus.

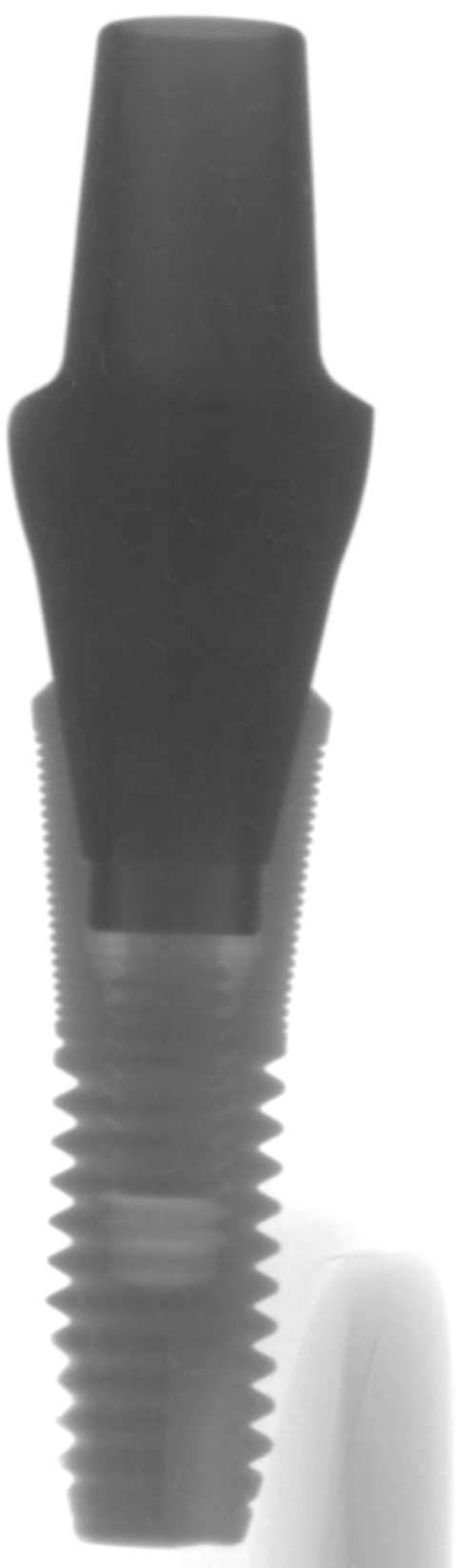

Figure 9: Radiographic picture for zirconia abutment-implant apparatus. 


\section{LPS LEAKAGE \\ FROM IMPLANT CHAMBER TO EXTERNAL MILIEU}

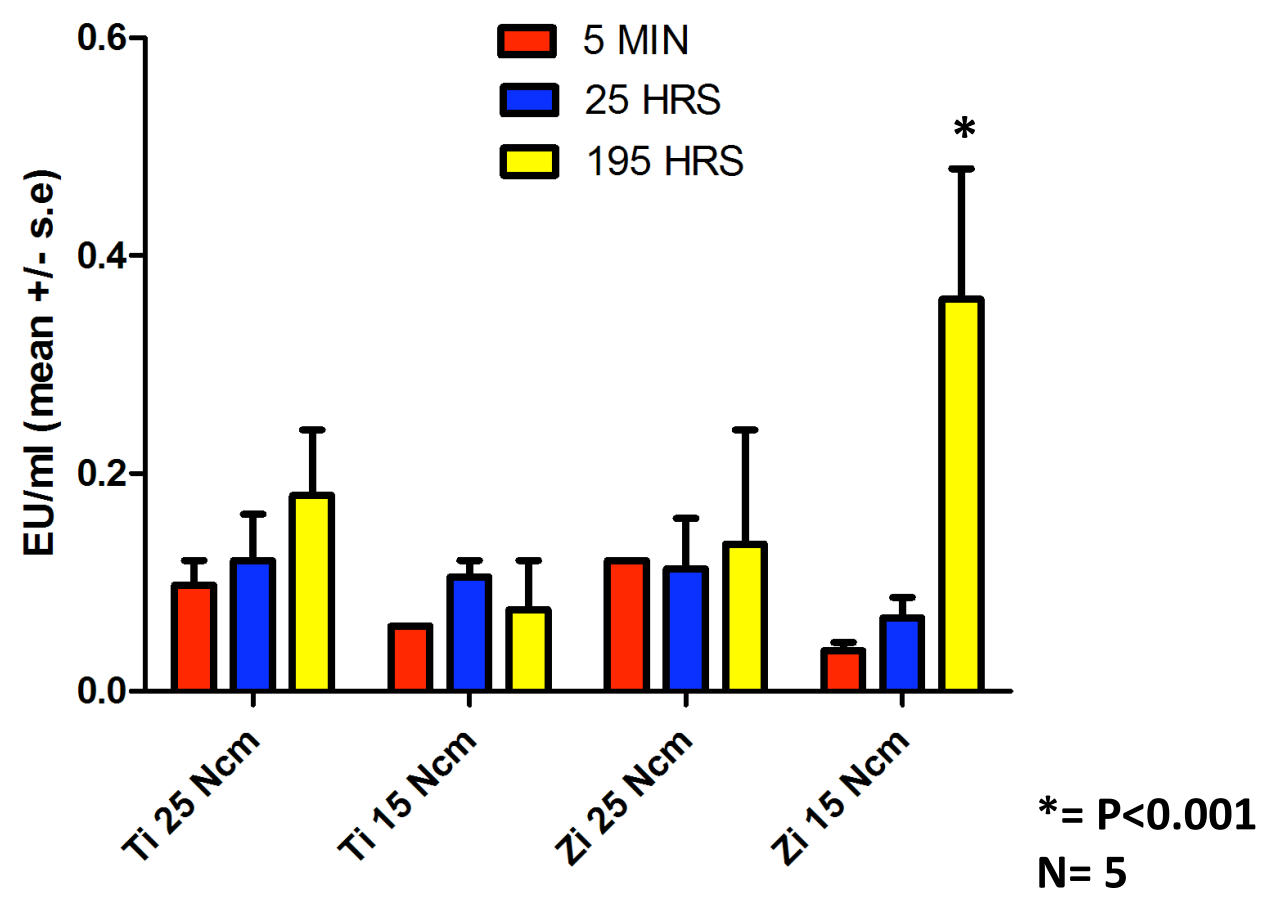

Figure 10: LPS microleakage from implant chamber into external milieu.

Data is expressed as LPS concentration detected within supernatant at different time points. 


\section{LPS LEAKAGE \\ FROM IMPLANT CHAMBER TO EXTERNAL MILIEU}

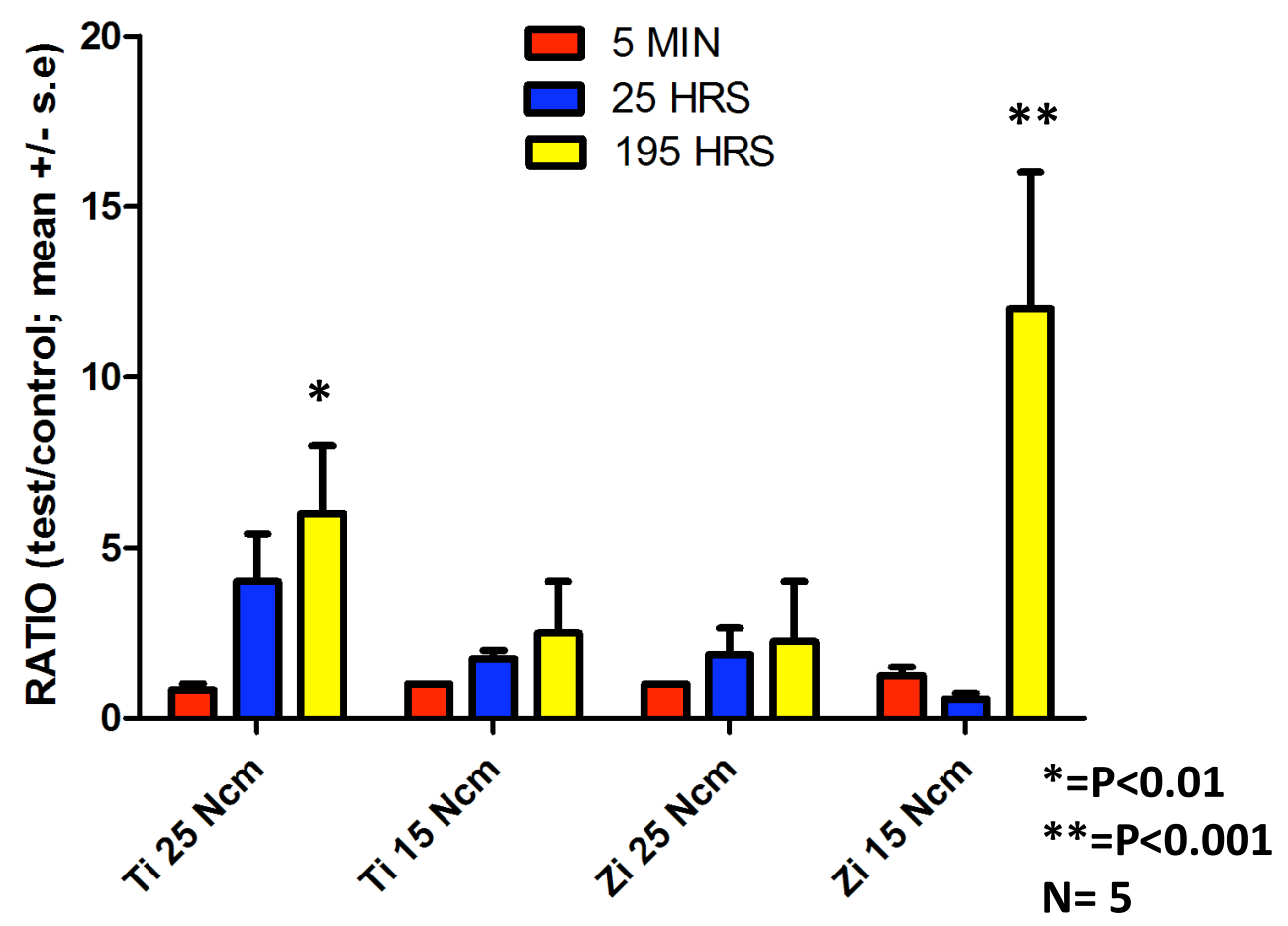

Figure 11: LPS microleakage from implant chamber into external milieu. Data is expressed as the ratio of LPS detected around test samples to LPS detected around negative control samples (e.g. implants with no E.coli LPS inoculation). 


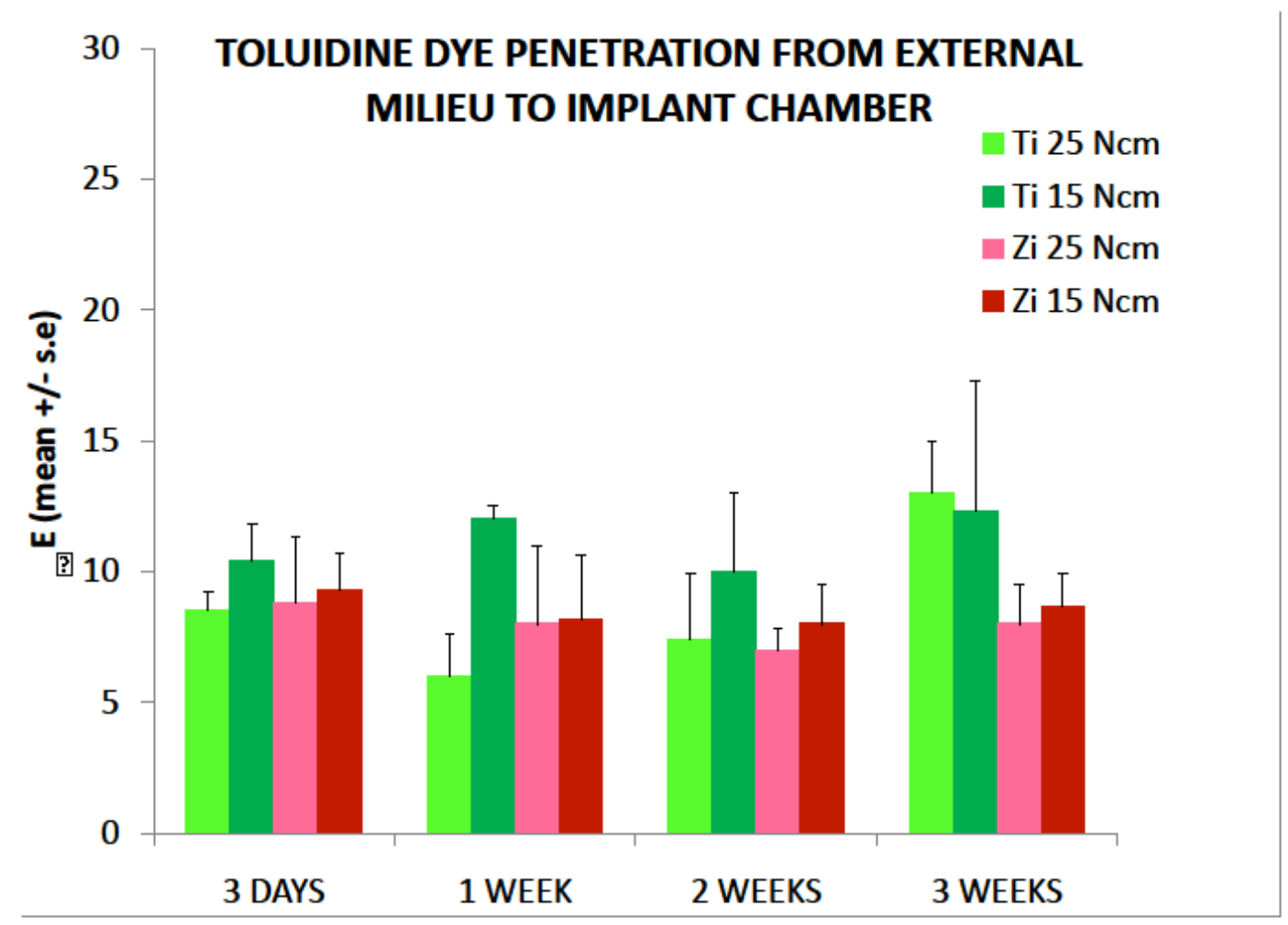

Figure 12: Toluidine dye penetration from external milieu into implant chamber. Data is expressed as mean $\Delta \mathrm{E} \pm$ s.e. (color change of paper dot). 


\section{TOLUIDINE DYE PENETRATION \\ FROM EXTERNAL MILIEU INTO IMPLANT CHAMBER- SCREW ACCESS HOLE ONLY}

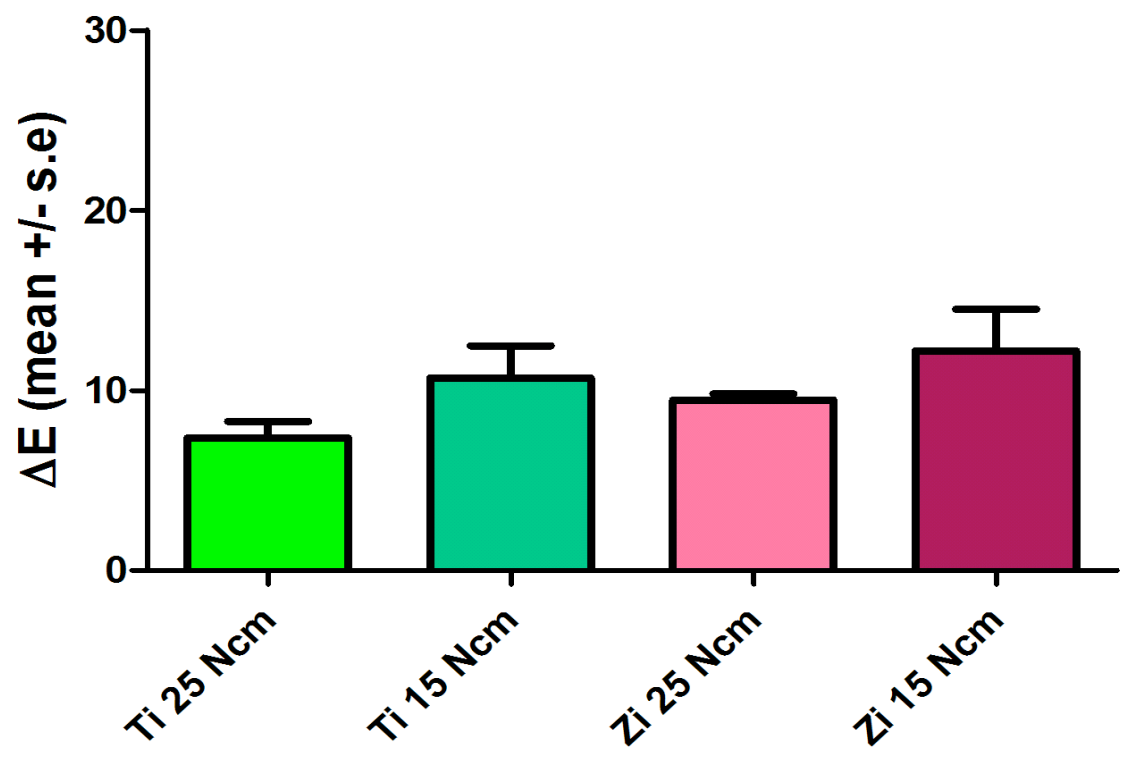

Incubati on ti $m e=3$ days

$\mathbf{N}=\mathbf{3}$

Figure 13: Toluidine dye penetration from screw access hole into implant chamber following 3 days incubation. Data is expressed as mean $\Delta \mathrm{E} \pm$ s.e. (Color change of paper dot). 

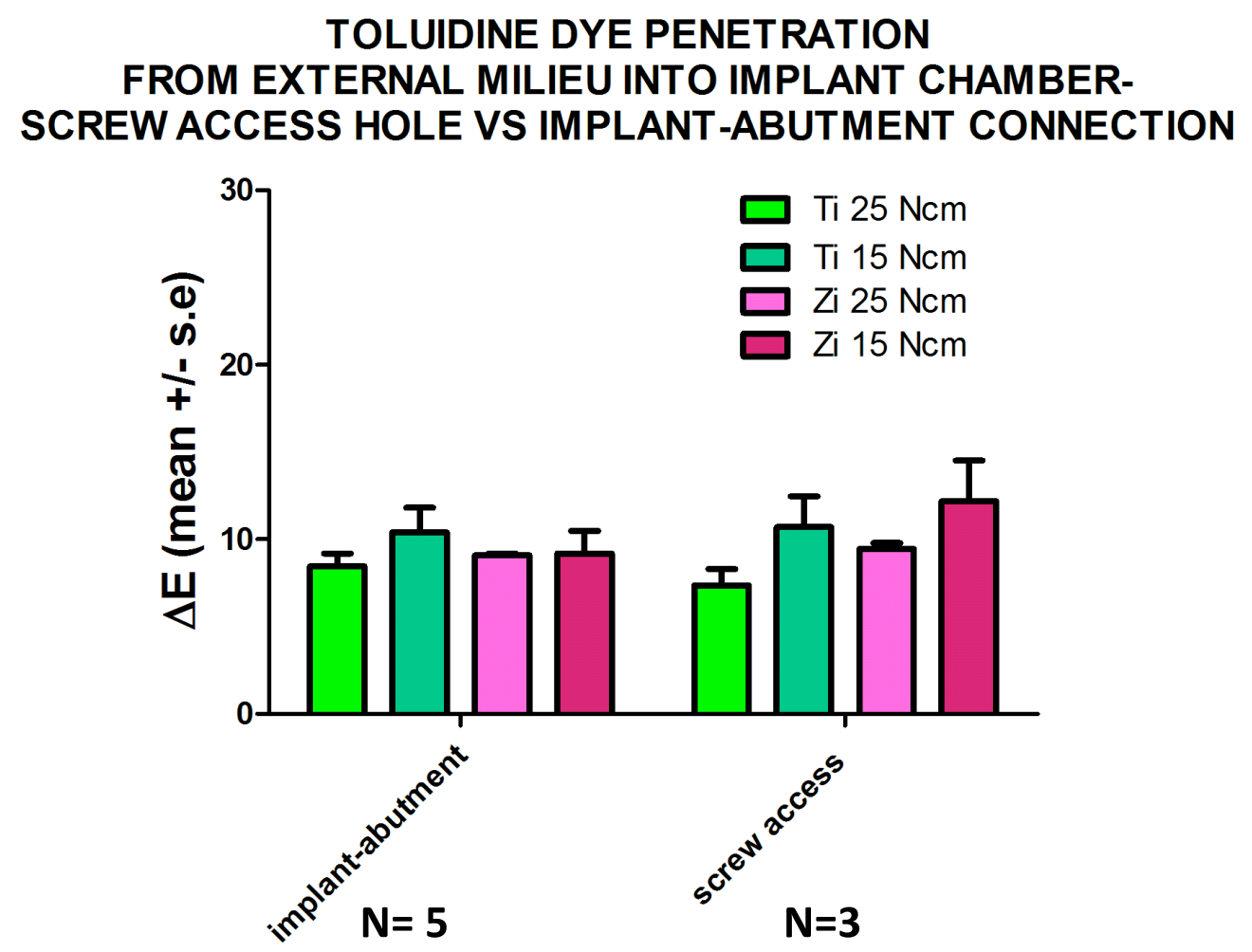

Figure 14: Toluidine dye penetration from screw access hole versus from implantabutment connection into implant chamber following 3 days incubation. Data is expressed as mean $\Delta \mathrm{E} \pm$ s.e. (Color change of paper dot). 


\section{TOLUIDINE DYE PENETRATION FROM EXTERNAL MILIEU INTO IMPLANT CHAMBER- MULTIPLE TORQUESIANTI-TORQUES}

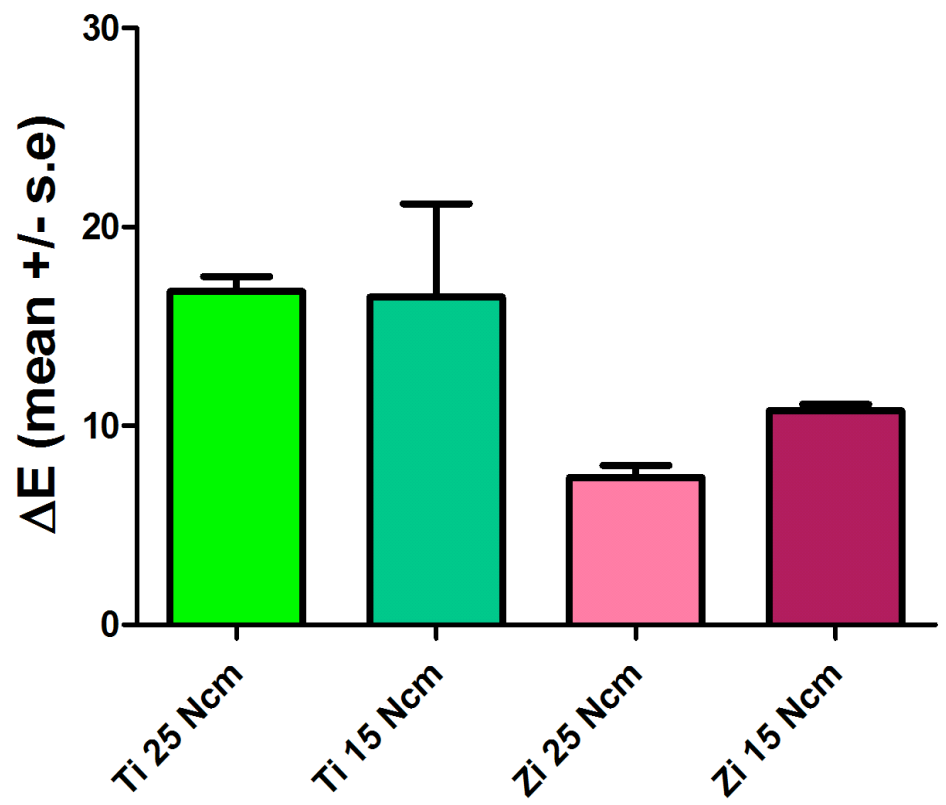

Incubati on ti me: $\mathbf{2}$ weeks

$\mathbf{N}=\mathbf{3}$

Figure 15: Toluidine dye penetration following several torquing/ anti-torquing. Incubation time for this experiment was 2 weeks. Data is expressed as $\Delta \mathrm{E}$ (color change of paper dot). 


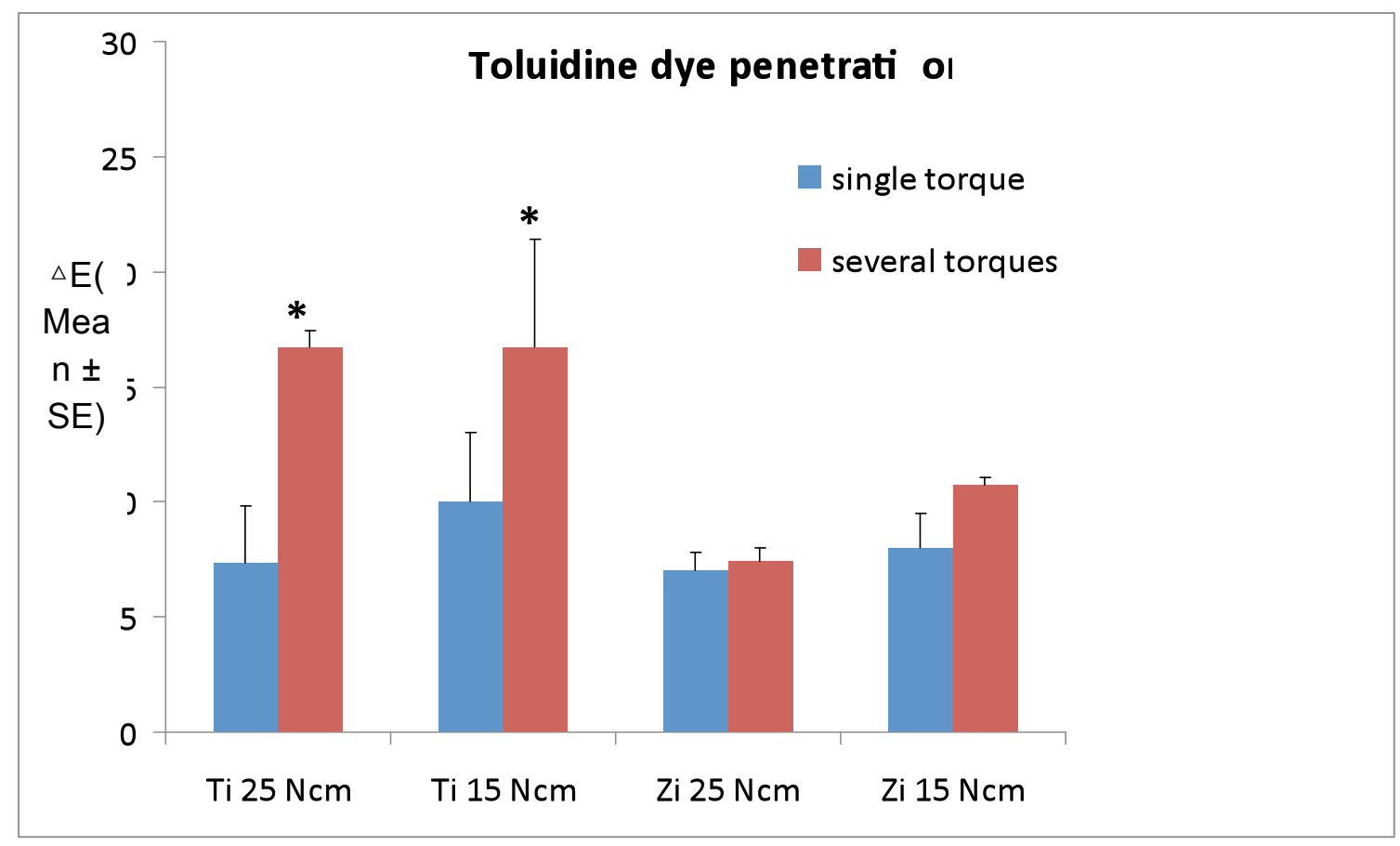

Figure 16: Toluidine dye penetration single torque vs several torquing/anti-torquing. Incubation time for this experiment was 2 weeks. Data is expressed as $\Delta \mathrm{E}$ (color change of paper dot). 


\section{Chapter 4}

\section{Discussion}

The aim of this study was to investigate microleakage at the implant/abutment interface using the two different abutments of the same design (titanium and zirconia abutments) and at varying torque values. An internal connection, locking taper implant system was

chosen for two reasons: less microleakage has been reported with tapered systems, ${ }^{15,38}$ and the implant body of the specifically chosen system has a significant internal chamber even after abutment screw connection which allowed for insertion of filter paper specimens without interfering with abutment seating. To verify seating, the implantabutment interface was studied using Micro-CT and high resolution radiography to determine whether insertion of paper specimens had created a gap, thus preventing complete seating of the abutment. Similar studies have chosen a SEM observational technique over micro CT and radiography to detect microgaps. The average microgap was found to be 2 to 7 microns for screw-retained abutments as investigated using the SEM technique ${ }^{18}$. The implant/abutment combination used in this study has a reported microgap ranging from 1 to 2 microns. ${ }^{15}$ The Micro-CT technique has a maximum resolution of 9.7 microns and would not be sensitive enough to detect the gap size found by SEM studies. The goal in using micro-CT technique in the current study was to detect any intentional space created by inserting filter paper specimens into the implant internal chamber. Also, this technology enabled the study of the implant-abutment connection in 
three dimensions, which is not possible with SEM and conventional radiographic techniques. High resolution radiography was chosen as an additional technique to evaluate the implant/ abutment interface to overcome the density differences between the zirconia and titanium materials.

In this study, bidirectional microleakage was studied by using two experimental methods: E.coli LPS inoculation of internal implant chamber followed by a LAL test, and incubation of the implant/abutment assembly in toluidine blue dye followed by colorimetric determination of dye penetration. Microbial penetration between implant components has been reported in the literature both by using in vitro study models and in clinical studies ${ }^{15,18,21,24,38,41,42}$. The internal part of the implant can be contaminated during implant placement and/or abutment placement. ${ }^{6}$ Thus, bacteria can grow inside the implant ${ }^{6}$ or within the peri-implant sulcus. ${ }^{28}$ Some researchers argue that these two biological sites are not connected and the bacteria isolated from these two sites on the same implant are significantly different ${ }^{6,7,24}$. In this aspect, penetration of bacterial byproducts instead of the bacteria themselves may play a more important role in periimplant pathogenesis. ${ }^{49}$ Thus, several in vitro microgap/leakage-related studies have chosen to evaluate bacterial byproducts instead of whole bacteria inoculation ${ }^{25}$. Among those byproducts; lipopolysaccharide (LPS) is well established. LPS, also known as lipoglycans, are large molecules consisting of a lipid and a polysaccharide joined by a covalent bond. They are found in the outer membrane of gram-negative bacteria, act as endotoxins and elicit a strong immune response in in vivo models ${ }^{25}$. Although they are considered large molecules, they are much smaller that a living bacterium (which ranges from 1 to 10 micron in size). ${ }^{6,7,21,44}$ LPS was chosen in this microleakage study since 
the reported microgap is small enough to stop most whole bacteria. E.coli LPS was preferred compared to other oral flora-related bacterial LPS since it is easily accessible and it is still relevant for oral cavity. ${ }^{50}$

Baseline LPS contamination is a commonly reported problem related to similar in vitro study models, since LPS can be easily found in the surrounding environment. Most of the published in vitro studies report several cycles of autoclaving and/or chemical processing to remove this type of baseline LPS prior to the actual experiment ${ }^{25,52}$. This procedure by itself may cause various problems since it may change structural integrity of materials and especially implant-abutment fit. According to FDA regulations, implant materials designed to be used for human body have very low levels of LPS that would not cause immune response activation. Thus, in this study the implant bodies and abutments were unpacked under a ventilation hood and LPS inoculation and abutment placement were conducted under sterile conditions. Also, some implants were not inoculated with LPS and were used to determine baseline levels of LPS contamination due to the environment. This study design helped to detect actual time-dependent LPS leakage from inoculated implants and compared it to LPS levels detected from non-inoculated implants without extra sterilization procedures. Similarly, LPS overflow due to torque forces is a possibility during abutment placement. The volume chosen for this study $(0.5 \mu 1)$ was very small and was previously reported for the type of implant and experimental design used in this study. ${ }^{25}$ Following each abutment placement and torque procedure, the implant/abutment assembly was examined for any leakage prior to exposing it to the Pyrotell water bath. In other studies, approximately $60 \%$ of the samples have been reported as contaminated immediately after inoculation with the same volume of LPS. ${ }^{15}$ 
However; their inoculation technique was different than the one used in present study; They inoculated the tip of the screw compared to inoculating the deepest part of implant internal chamber. ${ }^{15}$ The results of the LPS leakage study (leakage from implant internal chamber into external supernatant) showed that leakage from the inside of the implant to the outside is time dependent and independent of the abutment type or the closing torque value, which is in agreement with results reported by Harder et al. ${ }^{25}$ Similarly, DoNascimento et al, compared microleakage using two different abutment systems (premachined and cast abutment) and showed that both systems have low percentage of microleakage and that there was no significant difference between different abutment systems in an unloaded condition. ${ }^{22}$ There are no studies available on microleakage related to zirconia abutments for comparison to the results of this study. An obvious time and abutment/torque dependent increase in LPS leakage was observed especially for titanium abutments torque at $25 \mathrm{Ncm}$ and zirconia abutments torque at $15 \mathrm{Ncm}$ (Figure 10 and 11). An increase was also noted for titanium abutments torqued at $15 \mathrm{Ncm}$ and zirconia abutments torqued at $25 \mathrm{Ncm}$, but this did not reach statistically significant levels. Faster leakage was observed for titanium abutments torqued at $25 \mathrm{Ncm}$ and this may be related to the higher torque value and titanium materials properties under higher torque pressure. Zirconia abutments torqued at $15 \mathrm{Ncm}$ initially showed very small amount of leakage. However, the increase in leakage for this group was almost 10 fold by $195 \mathrm{hrs}$ compared to $5 \mathrm{~min}$ incubation. This may be again due to a lower torque value and the zirconia materials properties under low torque pressure [As Zirconia is much harder than Titanium this may result a tighter seal when the Zirconia abutments are 
torqued against Titanium implant body. On the other hand, there is not such a tight seal when Titanium abutments are torqued against Titanium implant body].

Microleakage through a possible microgap from the external milieu into the implant internal chamber was investigated by placing two $1.5 \mathrm{~mm}$ diameter filter paper specimens inside the chamber. The implant/abutment assembly was tightened using two different torque values and incubated in toluidine dye at $37^{\circ} \mathrm{C}$. Similar studies using same technique have been already published ${ }^{18}$. The main difference for the current experimental protocol was that a colorimeteric analysis of the retrieved paper specimens allowed generation of calibrated numeric data which would be impossible with naked eye evaluation even under magnification. Piattelli et al, reported dye leakage into the internal part of implant with two different abutment systems (screw retained vs. cement retained abutments) following $30 \mathrm{hrs}$ incubation. ${ }^{18}$ In the case of cemented abutments, a sectioning procedure had to be used in order to retrieve the filter paper. Stereomicroscopy was used to evaluate the internal threads of the implant for possible dye penetration. They concluded that there was no leakage in cement-retained abutments due to cement filling the microgap. Dye penetration into most apical portion of the internal implant chamber instead of just the internal threads was investigated in the current study. However, internal threads were also examined under magnification and additional light source. It was noted that, although there was not significant leakage detected by filter paper dots at the 3 day and 1 week incubation periods, leakage from the screw access hole to the implant/abutment interface (most apical portion of abutment recovered with toluidine blue dye) was a general finding with faster leakage observed in abutments torqued at $15 \mathrm{Ncm}$. There was no detectable contamination on internal 
threads. Similarly, Gross et $\mathrm{al}^{26}$, used the dye penetration technique to compare microleakage in five different implant systems under three different torque values. They introduced $2 \mathrm{~atm}$ pressure to drive the dye through the interface and to overcome the problem of air entrapment. They also created a channel at the base of the implant for pressurized dye to have access to the inside of the implant chamber. Their results showed that there was an increase in microleakage overtime for all tested implant systems and the microleakage decreased by increasing the closing torque value from $10 \mathrm{Ncm}$ to $20 \mathrm{Ncm}$ and to the manufacturer's recommended torque value. They also reported that there was more leakage of conical connections, than flat peripheral connection. Atmospheric pressure was not applied in the current study to control dye flow into internal part of the implant. However, $20 \mu 1$ toluidine blue dye was initially placed into screw access hole and pipetted in and out to remove any possible air bubbles. Then, the implant-abutment apparatus was placed inside a test tube and test tube was filled with toluidine blue dye or sterile water (up to the most coronal part of implant-abutment apparatus). This handling protocol helped control screw access hole space following different torques (each hole took exactly $20 \mu 1$ total dye volume determining correct screw placement) and also controlled any possible air bubbles trapped within the dye solution. In the current study, there was not a statistically significant increase in dye leakage from the external milieu to the most apical internal part of the implant at three days or one week. However, obvious leakage reaching to the most apical portion of internal chamber was noted with increasing incubation period. This increase in bidirectional microleakage with time has been confirmed by other studies. ${ }^{26,23}$ 
The results of the current study show a statistically significant effect of repeated torquing on microleakage for Titanium abutments, although a trend was also noted for Zirconia abutments. The effect of repeated torquing was previously reported in the literature for titanium abutments ${ }^{46}$ and was attributed to the decrease in the preload value decreasing the clamping force between implant and abutment. ${ }^{50}$

Finally, this in vitro study aimed to investigate bidirectional microleakage in a non-loaded environment. It has been reported that loading the implant-abutment assembly induces micromotion between these two pieces. ${ }^{21}$ It has been hypothesized that this micromotion depends on the structural strength of the implant abutment connection. ${ }^{21}$ Thus, loading may have a significant effect on bidirectional microleakage results reported in the current study.

Within the limits of this in vitro study, it can be concluded that there is an increase in microleakage in general with time even in non-loaded conditions. This increase is statistically significant for leakage from internal chamber to external milieu for Titanium abutment torqued at high values and Zirconia abutments torqued at low values. While a trend exists for increasing leakage from external milieu into internal chamber for Titanium abutments torqued at both high and low values. In addition, it becomes statistically significant for Titanium abutments with repeated torque/antitorques. Leakage from external milieu into internal chamber is similar from screw access hole compared to abutment-implant connection. Additional in vitro and in vivo studies are necessary to determine the effect of this bidirectional microleakage on peri-implant tissues around zirconia abutments. Also, this in vitro study should be repeated under 
loading conditions to determine differential effect of loading on bidirectional microleakage around zirconia abutments. 


\section{REFERENCES}

1-Adell R, Lekholm U, Rockler B, et al, A 15 year study of osseointegrated implants in the treatment of edentulous jaw. Int J Oral surgery 1981; 10:387-416

2- Albrektsson T, Zarb GA, Worthington P, et al. The long term efficacy of currently used dental implants: A review and proposed criteria of success. J Oral and Maxillofacial Implants. 1986; 1(1)11-25.

3- Adell R, Eriksson B, Lekholm U, et al. Along term follow up study of osseointegrated implants in treatment of totally edentulous jaw. Int $\mathrm{J}$ Oral and Maxillofacial Implants.1990; 5:347

4-Alberktsson T. long-term maintenance of osseointegrated response. Australian Prosthodontics Journal. 1993; 7:15-24.

5-Zambon JJ, Periodontal disease: Microbial factors. Ann Periodontal 1996; 1:879-925

6-Quirynen M, Van Steenberghe D. Bacterial colonization of the internal part of two stage implants. An in vivo Study, Clin Oral Implant Res. 1993; 4:158-161.

7-Quirynen M, Bollen CML, Eyssen H, et al Microbial penetration along the implant components of the Branemark system. An in-vitro study. Clin Oral Implants Research. 1994; 5:239-244.

8-Listgarten M. Microorganisms and dental implants (editorial). J Periodontol 1999; $70: 220-222$.

9-Smith DE, Zarb GA, Criteria for success of osseointegrated endosseus implants. J Prosth Dent, 1989, 62; 5:567-572.

10-Esposito M, Hirsch JM, Lekholm U, et al. Biological factors contributing to failures of osseointegrated oral implants (1) Success criteria and epidemiology. Eur J Oral Sci $1998 ; 106: 527-551$.

11- Aloise JP, Curcio R, Laporta MZ, et al , Microbial leakage through the implantabutment interface of morse taper implant in Vitro .Clin Oral Implant Res 2010; 21:328325. 
12-Orsini G, Fanali S, Scarano A, et al, Tissue reaction, fluids, and bacterial infiltration in implants retrieved at autopsy: a case report, Int J Oral Maxillofacial Implants 2000; $15: 283-286$

13-Berglundh T, Lindhe J, Marinello C, et al, Soft tissue reaction to de novo plaque formation on implants and teeth. An experimental study in the dog.1992, Clin Oral Implants Res, 1992:3; 1-8

14-Ericson I, Berglundh T, Marinello C, et al. Long-standing plaque and gingivitis at implant and teeth in the dog. Clin Oral Implant Res 1992; 3:99-103.

15- Jansen VK, Conards G, Richter EJ, et al. Microbial leakage and marginal fit of implant-abutment interface. Int J Oral Maxillofacial Implants.1997 Jul-Aug; 12(4):52740 .

16- Ericson I, Person LG, Berglundh T, et al, Different types of inflammatory reaction in peri-implant soft tissues. J Clin Periodontol 1995; 22:255-261.

17- Broggini N, McManus LM, Hermann JS, et al. Peri-implant inflammation defined by the implant-abutment interface .J Dent Res .2006May; 85(5):473-8.

18- Piattelli A, Scarano A, Paolantonio M, et al. Fluid and Microbial penetration in the internal part of cement-retained versus screw retained implant-abutment connection. J Periodontol 2001; 72:1146-1150.

19- O'Mahony A, MacNeil S, Cobb C. Design features that may influence bacterial plaque retention: A retrospective analysis of failed implants. Quintessence Int 2000; 31:249-256.

20- Serge D, Martha W, Fan Su M, et al. In vitro evaluation of the implant-abutment bacterial seal: The locking taper system. Int J Oral and Maxillofac Implants 2005; 20:732-737.

21- Steinebrunner L, Wolfart S, Bobbman K, et al. In vitro evaluation of bacterial leakage along the implant-abutment interface of different implant systems. Int $\mathrm{J}$ Oral and Maxillofacial Implants.2005; 20:875-881.

22-DoNascimento C, Barbosa RS, Watanabe E, et al. Bacterial leakage along the implant-abutment interface of premachined or cast components .Int J Oral Maxillofac surg 2008; 37(2):177-180.

23- Guindy JS, Besimo CE, Besimo R, et al. Bacterial leakage into and from prefabricated screw-retained implant-borne crowns in vitro. Journal of oral Rehabilitation 1998; 25:403-408. 
24- Persson LG, Lekholm U, Leonhardt A, et al. Bacterial colonization on the internal surface of Branemark system implant components. Clin Oral Implant Research 1996; 7:90-95

25-Harder S, Dimaczek B, Acil Y, et al. Molecular leakage at implant-abutment connection. In vitro investigation of tightness of internal conical implant-abutment connection against endotoxins penetration. Cli Oral Invest.2009.

26- Gross M, Abramovich I, Weiss E. Microleakage at the abutment-implant interface of osseointegrated implants: a comparative study .Int J Oral Maxillofac implants .1999Jan Feb; 14(1):94-100

27- Socransky SS, Smith C, Martin L, et al. Checkboard DNA -DNA hybridization. Biotechniques 1994; 17:788-792.

28-DeAngelo S, Kumar P, Beck F, et al, Early soft tissue healing around one stage dental implants: Clinical and Microbiological parameters, J Periodontology. 2007 vol 78; 10:1878-1886.

29- Barbosa RS, Nascimento CD, Issa JM, et al, Bacterial culture and DNA Checkboard for the detection of internal contamination in Dental Implants. Journal of Prosthodontics 2009 ; 18:376-381.

30- Rack A, Rack T, Stiller M et al. In Vitro synchrotron based radiography of microgap formation at the implant-abutment interface of two-piece dental implants. $\mathrm{J}$ of Synchrotron Radiation 2010, 17, 289-294.

31-Binon P. Int J Oral Maxillofac Implant .2000; 15:76-95.

32- Broggini N, McManus LM, Herman JS, et al. Persistent acute inflammation at the implant-abutment interface. .J Dental Res 2003;82(3):232-237.

33- Hermann JS, Schoolfiel JD, Schenk RK, et al. Influence of the size of microgap on crestal bone changes around titanium implants. A histometric evaluation of unloaded non-submerged implants in the canine mandible. J Periodontology.2001Oct; 72(10)137283.

34-Hermann JS, Buser D, Schenk RK et al, Biological width around one- and two-piece titanium implants. A histometric evaluation of unloaded nonsubmerged and submerged implants in the canine mandible. Clin Oral implants Res 2001.

35- Tasi N, McManus LM, Oates, et al. An evaluation of inflammation associated with the implant/abutment interface. J Dent Res2000 (Sept issue); 79:168(Abstr). 197.

36- Lazzara RJ, Porter SS. Platform switching: A new concept in implant dentistry for controlling postrestorative crestal bone level. Int J Periodont Restor Dent.2006 26:9. 
37- Lavlle C, Wedgwood D, Riess G. New implant philosophy. J Prosth Dent, 1980 Jan; 43(1)71-77.

38- Dibart S, Warbington M, Fan Su M. et al. In vitro evaluation of the implant-abutment bacterial seal: the locking taper system. Int J Oral Maxillofac implants .2005 Sep-Oct; 20(5):732-7.

39- Hurzeler M, Fickl S, Zuhr O, et al. Peri-Implant bone level around implants with platform switched abutments: Preliminary data from a prospective study. J Oral and Maxillofac Surg 2007; 65:33-39, suppl 1.

40-Nevins M, Nevins Marcel, Camelo M, et al, Human Histologic evidence of connective tissue attachment to dental implants. Int J Periodontic and Restorative Dent .2008; 28, 2:111-121.

41- Duarte AR, Rossetti PO, Rossetti LN, et al. In Vitro sealing ability of two material at five different implant-abutment surfaces. J Periodontol .2006Nov; 77(11):1828-32.

42- Proff P, Steinmetz I, Bayerlin T, et al. Bacterial colonization of interior implant threads with and without sealing. Folia Morphol.2006; 65(1):75-77.

43- Groenendijk E, Dominicus J, Moorer W, et al. Micorbiological and Clinical effect of Chlorhexidine enclosed in Fixture of 3I Titamed implants. Clin Oral Implant Res 2004; 15:174-179

44- Besmio CE, Guindy JS, Lewetag D, et al. Prevention of bacterial leakage into and from prefabricated screw retained crowns on implants in vitro. Int J Oral and Maxillofac Implants 1999; 14:654-660.

45- Weiss EI, Kozak D, Gross MD, Effect of repeated closures on opening torque values in seven abutment-implant systems. Journal of Prosthetic Dentistry 2000; 84:194-199.

46- Nascimento C, Pedrazzi V, Miani PK, et al. Influence of repeated screw tightening on bacterial leakage along the implant-abutment interface. Clin Oral Implant Res 2009; 20:1394-1397.

47-Haack JE, Sakaguchi RL, Sun T et al, Elongation and preload stress in dental implant abutment screw. Int J Oral Maxillofac Impl 1995; 10:529-535

48-Internationl Commission On Illumination Colorimetry $2^{\text {nd }}$ Edition Publication CIE No 15. 2 (1986)

49-Niar SP, Meghji S, Wilson M, et al, Bacterially induced bone destruction: Mechanism and misconceptions, Infect Immun 1996; 64:2371-2380 
50-Wahl G, Muller F, Schaal KP. The microbial colonization of implant elements made of plastic and titanium. Schweiz Monatsschr Zahnmed 1992; 102:1321-1326

51-Byrne D, Jacobs S, O’Connell B, et al. Preload generated with repeated tightening in three types of screws used in dental implant assembly. J Prosthodontics 2006; 15:164-71

52-Nataka T. Destruction of Challenged Endotoxins in a dry heat oven, J Pharm Sci Technol; 1994, 48:59-63. 